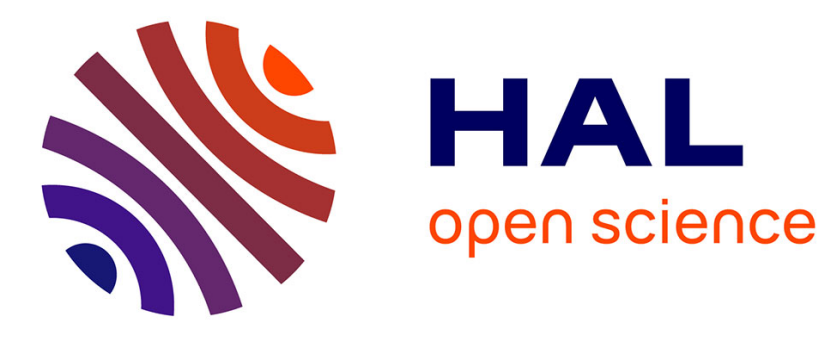

\title{
Design theory at Bauhaus: teaching 'splitting' knowledge
}

Pascal Le Masson, Armand Hatchuel, Benoit Weil

\section{To cite this version:}

Pascal Le Masson, Armand Hatchuel, Benoit Weil. Design theory at Bauhaus: teaching 'splitting' knowledge. Research in Engineering Design, 2016, 27, pp.91 - 115. 10.1007/s00163-015-0206-z . hal-01481058

\section{HAL Id: hal-01481058 \\ https://hal-mines-paristech.archives-ouvertes.fr/hal-01481058}

Submitted on 2 Mar 2017

HAL is a multi-disciplinary open access archive for the deposit and dissemination of scientific research documents, whether they are published or not. The documents may come from teaching and research institutions in France or abroad, or from public or private research centers.
L'archive ouverte pluridisciplinaire HAL, est destinée au dépôt et à la diffusion de documents scientifiques de niveau recherche, publiés ou non, émanant des établissements d'enseignement et de recherche français ou étrangers, des laboratoires publics ou privés. 
Le Masson, P., Hatchuel, A., and Weil, B. (2015). " Design Theory at Bauhaus: teaching "splittin knowledge." Research in Engineering Design, (accepted)

\title{
Design Theory at Bauhaus: teaching "splitting" knowledge
}

\author{
Authors: \\ Pascal Le Masson, Armand Hatchuel, Benoit Weil \\ MINES Paristech - PSL Research University \\ CGS - i3 UMR CNRS 9217 \\ Corresponding author: pascal.le masson@mines-paristech.fr - tel: +33140519221
}

\begin{abstract}
Recent advances in design theory help clarify the logic, forms and conditions of generativity. In particular, the formal model of forcing predicts that high-level generativity (so-called generic generativity) can only be reached if the knowledge structure meets the 'splitting condition'. We test this hypothesis for the case of Bauhaus (1919-1933), where we can expect strong generativity and where we have access to the structures of knowledge provided by teaching. We analyse teaching at Bauhaus by focusing on the courses of Itten and Klee. We show that these courses aimed to increase students' creative design capabilities by providing the students with methods of building a knowledge base with two critical features: 1) a knowledge structure that is characterized by non-determinism and nonmodularity and 2) a design process that helps students progressively 'superimpose' languages on the object. From the results of the study, we confirm the hypothesis deduced from design theory; we reveal unexpected conditions on the knowledge structure required for generativity and show that the structure is different from the knowledge structure and design process of engineering systematic design; and show that the conditions required for generativity, which can appear as a limit on generativity, can also be positively interpreted. The example of Bauhaus shows that enabling a splitting condition is a powerful way to increase designers' generativity.
\end{abstract}

\section{Keywords:}

Generativity, design theory, splitting condition, Bauhaus, industrial design 


\section{Introduction}

What is the logic of creative reasoning? Recent advances in design theory have provided answers to debates on the possibility of any logic of creation and have allowed the analysis, modelling, and even improvement of the generativity capacities of creative people. There are models of generativity (Hatchuel et al. 2011). They describe, for instance, generativity that involves mixing 'non-alignment'-based concepts (Taura et Nagai 2013), generativity that relies on duality inside the knowledge space (Shai et Reich 2004a; Shai et al. 2013), generativity that relies on closure spaces (Braha et Reich 2003), or generativity that involves adding to a concept attributes that break design rules (i.e., C-K expansion (Hatchuel et Weil 2009)).

Based on these models, design theories provide an enriched vocabulary for the creative 'outcome'; e.g., there are designed entities at the borders of different semantic fields (i.e., general design theory (Taura et Nagai 2013)), designed entities that fill in 'holes' (i.e., infused design (Shai et Reich 2004a; Shai et al. 2013)), and designed entities that create new identities and new definitions of things (i.e., C-K theory (Hatchuel et Weil 2009)). The models also provide enriched descriptions of how design unfolded to get these entities; e.g., knowledge provoking 'blending' (i.e., general design theory), the uncovering of 'holes' via duality (i.e., infused design), and the use expansive partitions (i.e., C-K theory).

The above works provide us with new approaches of creation and creative reasoning. In particular, the models predict that strong generativity (which we later call 'generic generativity') is associated to (and, more precisely, conditioned by) specific knowledge structures; i.e., the knowledge base has to follow a splitting condition. This proposition is counter-intuitive as we tend to rather consider that the only limits to generativity are cognitive fixations. Hence, the present paper addresses the issue of whether we can verify the splitting condition in design situations that are particularly generative. If the splitting condition is true, it should be, for instance, particularly visible in the case of so-called 'creative professions' like art and industrial design. We therefore ask: Relying on design theories, can we characterize a type of generativity of industrial designers-specific 'effects'-and specific conditions acting on the knowledge structure that help achieve these effects? We do not study all industrial designers and rather focus on industrial design schools because they are the places where industrial designers are educated (and thus provide favourable access to knowledge bases) and where a doctrine of what is industrial design, and particularly its logic of generativity, is discussed, practiced and diffused. We focus on one of the most famous industrial design schools, Bauhaus, for many the matrix of several industrial design schools of today.

How does Bauhaus relate to generativity? Indeed, teaching industrial design does not necessarily consist of increasing creative design capability as it can also involve teaching existing styles and processes (e.g., drawing and moulding). Bauhaus itself was from time to time assimilated in a new style (e.g., the functionalist style); one can be tempted to think that the school actually taught this functionalist style. We therefore first clarify whether Bauhaus teaching really consists of teaching creative design methods (and theories) or only involves teaching a new 'style'. More generally, we will characterize the kind of creative expansion that Bauhaus teaching is expected to generate. We will show that Bauhaus actually aimed at a form of style creation, and we will show that this style creation can be characterized as a form of 'generic generativity'. We will then uncover critical facets of the reasoning that leads to this 'generic generativity'. On the one hand, the creative craft of the 
industrial designer is often viewed as a mysterious talent, reserved to those that are naturally born 'creative'(Weisberg 1992), and we will try to shed some light on this 'magical' talent. On the other hand, one might claim that the specificity of industrial designers is only a result of the type of knowledge industrial designers use (e.g., knowledge about users, ergonomics, symbolic meaning, sociology, culture, and form), and we will challenge the idea that industrial design is limited to certain areas of expertise. We will show that there is something more specific and more universal in Bauhaus teaching. Specifically, at Bauhaus, the capacity for design generativity is based on the acquisition of one very specific knowledge structure, characterized by two properties: non-determinism and non-modularity. We show that this knowledge structure corresponds surprisingly well to the so-called splitting condition in formal design models of mathematics.

Hence, we will characterize Bauhaus teaching as a way of helping students to be 'generically creative' by building a knowledge structure that meets the splitting condition.

Finally, we show that this study of teaching in industrial design is also relevant to engineeringdesign. How can this be? Industrial design and engineering design are two clearly distinct traditions (see histories on engineering design (Heymann 2005; König 1999) and industrial design (Forty 1986) and the relationship between engineers and so-called 'artists' (Rice 1994)), two different professions, not taught in the same schools and embodying two different social roles. The contrasting figures of industrial design and engineering design use different journals, rely on different epistemologies, and connect to different disciplines. Still, engineering design and industrial design today share common interests. Design research societies try to bring them together through joint conferences. Both communities share today a concern about creative design and innovative design capabilities. Furthermore, recent progress in design theory has helped uncover the universality of design beyond professional traditions (Le Masson, Dorst et Subrahmanian 2013) (see also recent keynotes on design theory at the International Conference on Engineering Design 2015, Milan, and at the European Academy of Design, Paris 2015), thus supporting scientific exchanges between communities. The present paper aims at contributing to this trend. Specifically, by relying on Bauhaus teaching and design theory, we expect to learn about not only industrial design but also the relationship between industrial design and engineering design and, more generally, we expect to enhance our understanding of innovative design capabilities and critical aspects of design theory.

We briefly review the literature on generative processes to formulate our research hypotheses (part 1), before presenting our method (part 2), our analysis of Bauhaus teaching, compared with engineering design (part 3), and our research results (part 4).

\section{Part 1: The logic of generativity and its formal conditions}

\section{Generativity as a unique feature of an ontology of design}

Works on design theory in recent decades have revealed that generativity is a critical, even unique, feature of design theory; see, in particular, the 2013 special issue on design theory published under Research in Engineering Design(Le Masson, Dorst et Subrahmanian 2013). This logic of generativity was analysed both from an historical perspective (Le Masson et Weil 2013; Le Masson, Hatchuel et Weil 2011) and from a formal perspective (Hatchuel, Weil et Le Masson 2013). It was shown that design theory is dealing with the emergence of new entities, previously unknown but designed by relying on known attributes; i.e., it 
addresses how to model the emergence of the new, the unknown, from the known. Different design theories proposed more or less generative models, relying on the specific language of the theory. As an historical example, one of the first design theories developed for machine design was the theory of ratios, developed by Ferdinand Redtenbacher (Redtenbacher 1852; König 1999). This theory is based on the language of each machine type (e.g., hydraulic wheels or a steam locomotive) and the generativity is thus limited to the machines described by the kind of language (e.g., the theory helps to generate previously unknown hydraulic wheels but cannot generate a turbine). Design theories have progressively increased their generative capacities by relying on abstract languages (or more precisely: on the abstract languages provided by the scientific advances of their time); e.g., general design theory relies on functions and attributes (Tomiyama et Yoshikawa 1986; Yoshikawa 1981; Reich 1995), the coupled design process overcomes the limits of functions by enabling the emergence of new functions (Braha et Reich 2003), infused design relies on duality in knowledge structures (Shai et Reich 2004a, b), and C-K theory relies on the logical status of propositions (Hatchuel et Weil 2009).

\section{Generativity and creativity-towards a variety of forms of generativity}

The different models highlight an overlooked area of research on creation and creativity: creative reasoning logic. Since the 1950s, psychologists have proposed measures of the effect of creative capacities (see Guilford criteria used to characterize a distribution of ideas - the fluency, diversity, originality of a set of ideas) (Guilford 1950). In the following years, many factors of creativity were identified (see Rhodes' 4Ps (person, process, press, products)) (Rhodes 1961). Still the reasoning logic of the creative mind has long remained out of scope. Several processes of creative reasoning have been proposed, all based on Wallas's model (information, incubation, illumination, verification)(Wallas 1926), itself already described by Poincaré (Poincaré 1908) (see also (Hadamard 1945)). In the 1990s, works on computer models of creativity were proposed. As underlined by (Boden 1999), they tended to distinguish between non-radical ideas, based on already known generative rules, and radically original ideas, which cannot 'be described and/or produced by the same set of generative rules as are other, familiar ideas' (p.40). Meanwhile, research in the field of psychology has underlined forms of 'bias' in creative design reasoning, leading to 'fixation effects' (Jansson et Smith 1991); i.e., distributions that are too narrow.

The above works focus on ideation and the psychology of ideation. Ideation is a part of design and often a phase in the design process. However, ideation does not account for all aspects of the generative process. In particular, ideation tends to rely on a 'closed-world assumption;; i.e., knowledge is given at the beginning of the ideation process. Hence, ideation cannot account for the generation of knowledge in design. Another limit is linked to the notion of an idea. Ideation focuses on the originality of one idea compared with other ideas, while generativity also accounts for the transformation induced by a designed entity; e.g., a newly designed entity might require/allow the re-ordering of the whole set of existing entities (i.e., new combinations between the new and the old are made possible and are accounted for by generativity). For instance, when Watt and Boulton designed a way to transform the parallel motion of the steam engine into a rotary motion, their design paved the way to new machines having several applications.

This discussion underlines that there are several forms and facets of generativitybeyond the quantity and originality of ideas. Generativity can also be characterized by knowledge creation and knowledge reordering induced by design. 


\section{Forms of generativity: 'generic' vs 'frequency' generativity}

Research that uses formal models helps uncover the variety of forms of generativity. The presentation of all these forms is beyond the scope of this paper. We discuss one of the most generative forms: generativity formalized by forcing.

Forcing is a method invented by Paul Cohen to create new models of sets (Cohen $2002,1966)^{1}$. Cohen presented forcing as a generalization of extension techniques (e.g., the creation of a field of complex numbers from fields of real numbers) or a generalization of the Cantor diagonal method (e.g., the creation of new reals). This generalization is powerful because sets are basic mathematical structures on which it is possible to reconstruct all mathematical objects (e.g., numbers, functions, geometry, algebra, and topological structures) (Dehornoy 2010) - hence the genericity of forcing. As shown by Hatchuel et al. (2013), forcing can be interpreted as a generic design method. Of course, its validity is limited to the design of new models of sets (while preserving some basis rules of sets (basically Zermello Fraenkel axioms)), but set theory is so general that it is possible to establish correspondences between the design of models of sets and the design of other entities, as shown by the correspondence between forcing and C-K theory (Hatchuel, Weil et Le Masson 2013).

Without going into every mathematical detail, let's underline a first main lesson from forcing: its generativity.

The logic of forcing is as follows (see (Cohen 2002; Jech 2002; Hatchuel, Weil et Le Masson 2013))

1) The first element of forcing is a so-called ground model $\mathrm{M}$ : a well formed collection of sets that is a model of the axiomatic of set theory, ie it follows Zermelo-Fraenkel axioms.

Illustration: this corresponds to the 'knowledge base' of the designer (e.g., knowledge of 'furniture'). As explained by (Dehornoy 2010), the logic of set theory roughly correspond to the intuition we can have on objects and sets of objects.

2) The second element is the set of so-called forcing 'constraints' built on $M$. To build new sets from $M$, we have to extract elements according to constraints that can be defined in $M$. Let us denote by $(Q,<)$ a set of constraints $Q$ and a partial order relation < on $Q$. This partially ordered set $(Q,<)$ is completely defined in $M$. Illustration: a piece of furniture has a shape, can meet functional requirements, and is made of materials. These are the 'constraints'. From $Q$, we can extract constraints that can form series of compatible and increasingly refined constraints $\left(q_{0}\right.$, $\left.q_{1}, q_{2} \ldots q_{i}\right)$, where for any $i, q_{i}<q_{i-1}$; this means that each constraint $q_{i}$ refines the preceding constraint $q_{i-1}$. The result of each constraint is a subset of $M$. Hence, the series $\left(q_{i}\right)$ builds series of nested sets, each one

\footnotetext{
${ }^{1}$ As suggested by an anonymous reviewer (whom we warmly thank), we provide here complementary references on forcing - these sources explore forcing historically:(Kanamori 2008; Moore 1988); the reader can also refer to (Chow 2009). (Dickman 2013) is a case study of creativity in science applied to the discovery of Forcing.

${ }^{2}$ In forcing theory, one uses interchangeably the terms "forcing constraint" and "forcing condition". In this paper, we favor the term "forcing constraint" to avoid confusion with the "splitting condition" that will be presented below.
} 
being included in its preceding set of the series. Such a series of constraints generates a filter $\mathrm{F}$ acting on $\mathrm{Q}$. A filter can be interpreted as a step-by-step definition of some object of $M . Q$ is the knowledgestructure used by the designer. Illustration: to define a certain piece of furniture, the designer can, for instance, describe the function, then the shape, then the materials (and hence there is a series of constraints that refine each other).

Illustration: in the world of industrial design, $\mathrm{Q}$ can have colour, texture, and be made of certain matter. In the world of engineering design, one would speak of functions, technologies, and organs.

3) The third element of forcing is the dense subsets of $(Q,<) . A$ dense subset $D$ of $Q$ is a set of conditions so that any condition in $Q$ can be refined by at least one condition belonging to this dense subset. One property of dense subsets is that they contain very long (almost 'complete') definitions of things (or sets) on $M$, because each condition in $Q$, whatever its 'length', can always be refined by a condition in D. Still, a dense subset contains only constraints so that it is a way to speak of all elements without 'having' one element and speaking of them only in terms of their 'properties'.

Illustration: in art, the notion of the 'balance' of the composition of a piece of art could be interpreted as a dense subset defined by conditions such as lines, colours, and masses. The set of conditions leading to a balance is dense in the set of all conditions because, whatever a sequence of conditions (a partially defined piece), it is always possible to identify additional conditions with which to speak of the 'balance' of this partially defined object. In engineering design, usual 'integrative' dimensions such as cost or weight, energy consumption or reliability can be considered as dense subsets. Whatever the level of definition of the machine at stake, there will always be a constraint that refines this level of definition and is related to, for instance, cost (or energy consumption, reliability, and so on). For instance, the issue of cost can be discussed when only functional constraints are added or it can be discussed much later in the design process when a detailed design is produced.

4) The fourth element (and core idea) of forcing is the formation of a generic filter $G$, made of constraints of $Q$ (hence from $M$ ), which step by step completely defines a new set. The exciting result of forcing is that, under certain conditions to be explained below, this new set defined by $\mathrm{G}$ is not in M. How is it possible to jump out of the box M? Forcing uses a very general technique in that it creates an object that has a property that no other object of $\mathrm{M}$ can have. Technically, a generic filter is defined as a filter that intersects all dense subsets. In general (see condition 1 below), this generic filter defines a new set that is not in $M$ but is still defined by conditions from $Q$, defined on $M$. We can interpret $G$ as a collector of all information available in $\mathrm{M}$ in order to create something new not in $\mathrm{M}$.

Illustration: in the case of industrial or engineering design, a new piece is only a filter (a series of constraints (i.e., lines, colours, and material), functions, technologies, organs, and dimensions). There is no guarantee that a series of constraints builds a generic filter; i.e., there is no guarantee that the series intersects all dense subsets and follows condition 1 below. There is thus no guarantee that the new piece is 'out-of-the-box'. However, conversely, as soon as the series meets condition 1 and intersects all dense subsets, one 
designs a new object that is made from the known constraints and is different from all the known objects.

5) The fifth element of forcing is the construction method for the extended model $\mathrm{N}$. The new set $\mathrm{G}$ is used as the foundation stone for the generation of new sets combining systematically $G$ with other sets of $M$ (usually denoted $M(G)$ ). The union of $M$ and $M(G)$ is the extension model $N$. Illustration: in the case of industrial design, a new object can embody a new style, and this new style can be used to redesign the whole set of known products, services, fonts and so on. A known example is the 'streamline' style that was used to redesign all kinds of products in the 1920s and 1930s (from aircraft to buildings, hairdryers, toasters and advertisement typography) (Engler et Lichtenstein 1990). In the case of engineering design, the development of a new machine is not supposed to lead to a revisit and redesign of the whole range of machines. Still, this can happen for so-called generic technologies; e.g., the development of electric motors and digital control systems led to the redesign of many systems and machine tools.

This leads us to the first powerful result of the mathematical model: it enables us to characterize 'generic' generativity. Let's explain this first point. Forcing creates a new set $\mathrm{G}$ that is built on $M$, and is, in general, different from all elements of $M$ and is still coherent with the rules of $M$. Therefore, this set $G$ is precisely 'generically' generative in that it is different from all elements of $M$ but coherent and able to lead to the design of a whole collection of new entities, $M(G)$. This 'generic generativity' can be distinguished from another type of generativity. Suppose that one distinguishes in $M$ the elements made only with 'usual' constraints and the elements made with at least one 'original' (i.e., rarely used) constraint. The latter constraints might be said to be creative in the sense that they are original, since they use a 'rarely used constraints'. However, these elements are in $M$. This is a form of 'frequency' generativity, which is non-generic. Note that an 'exploration' logic in a complex search space leads to 'frequency' generativity; i.e., the new solution will rely on a rarely used routine (constraint) but this solution is still in the initial space of potential solutions.

If the set is in $M$, then the 'composition' (union, intersection, and so on of all operations allowed by Zermelo-Fraenkel axioms) of this set with sets of $M$ is still in $M$; i.e., it is not 'new'. By contrast, if the set is not in $M$, then the composition of this 'new' set with sets of $M$ is also a new set. Hence, there is the process of extending $M$ to $N=M(G)$. In summary, in the case of 'frequency' generativity, one stays in the box (i.e., the generativity is simply related to the fact that one uses an 'original', low-frequency constraint from the box $M)$, and the new entity does not require the redesign of other entities. In the case of generic generativity, one uses constraints from the box $M$ to go out of the box ( $G$ is not in $M$ ) and this leads to the design of all-new objects created from the combinations of the new entity $G$ and the known entities in $\mathrm{M}$.

This formal model clarifies two very different forms of generativity and leads to the first research hypothesis in our study of creative designers:

$\mathrm{H1}$ : creative design aims at generic generativity.

By contrast, designers who don't claim creative design rather rely on non-generic generativity. 


\section{Conditions of generativity: splitting condition and countable dense subsets}

Forcing models are a powerful form of generativity-a form that seems to correspond to phenomena of strong generativity, such as the design of a new style in industrial design, the design of a generic technology in the realm of technical objects, or even the design (discovery) of new scientific principles in the realm of science (see the emergence of relativity theory or quantum theory in physics for instance).

Forcing also clarifies some conditions of this generativity. Note that this is not intuitive in that one tends to consider that there are only psychological limits to generativity, such as fixations. Forcing theory provides us with a characterization of the formal conditions associated to generic generativity. In technical terms, forcing clarifies the conditions required for a filter to be a generic filter that goes out of $M$.

There are two conditions sufficient to create a 'generic filter': the splitting condition and countability condition.

\section{Condition 1: splitting condition (necessary condition)}

A generic filter does not necessarily go out of $M$. It has been shown that $G$ is not in $M$ as soon as $Q$ follows the splitting condition; i.e., for every constraint $p$, there are two constraints $q$ and $q$ ' that refine $p$ but are incompatible (where the term 'incompatible' means that there is no constraint that refines $q$ and $\left.q^{\prime}\right){ }^{3}$

This formal expression corresponds to deep and general properties of the knowledge base of a designer (where we remember that $\mathrm{M}$ can be assimilated to the knowledge base of a designer and $Q$ to the structure of this knowledge base). Let's clarify what the splitting condition means. It is easier to understand what a non-splitting knowledge base is. A knowledge base is non-splitting in two cases.

1 -Deterministic rule: the knowledge base is non-splitting if there is one constraint $p$ such that there is only one single series of constraints $q_{1}, q_{2} \ldots$ that refines $p$ (see figure 1 ). This means that $p$ determines immediately the set of constraints that follows. $p$ is a deterministic rule that determines the entity. If there is such a deterministic rule, then the generic filter that contains $p$ does not go out of $M$.

This kind of deterministic rule can be found when the designer relies on one specific know-how or considers that he or she applies scientific rules and principles. In both cases, the designer follows a unique predefined series of constraints after $p$. As a consequence, design can be generically generative only if the designer does not only rely on know-how.

2-Modularity: the knowledge base is non-splitting if there is one constraint $p$ such that there are refinements $q$ and $q^{\prime}$ of $p$ such that there is a constraint $r$ that refines $q$ and $q^{\prime}$. This means that $q$ and $q^{\prime}$ are modules that can be added to the entity without making any difference to the following constraint $r$. $r$ is insensitive to the choice between $q$ and $q^{\prime}$. $q$ and $q^{\prime}$ are modular; i.e., they are interchangeable.

This kind of modularity can be found when the designer relies on building blocks that are interchangeable, such as Lego blocks. As a consequence, design can be generically generative only if the designer is not relying only on building blocks.

\footnotetext{
${ }^{3}$ Demonstration (see (Jech 2002), exercise 14.6, p. 223): Suppose that $G$ is in $M$ and consider $D=Q \backslash G$. For any $p$ in $Q$, the splitting condition implies that there are $q$ and $q^{\prime}$ that refine $p$ and are incompatible; one of the two is therefore not in $\mathrm{G}$ andthus is in $\mathrm{D}$. Hence, any condition of $Q$ is refined by an element of $D$. Hence, $D$ is dense. Therefore, $G$ is not generic.
} 

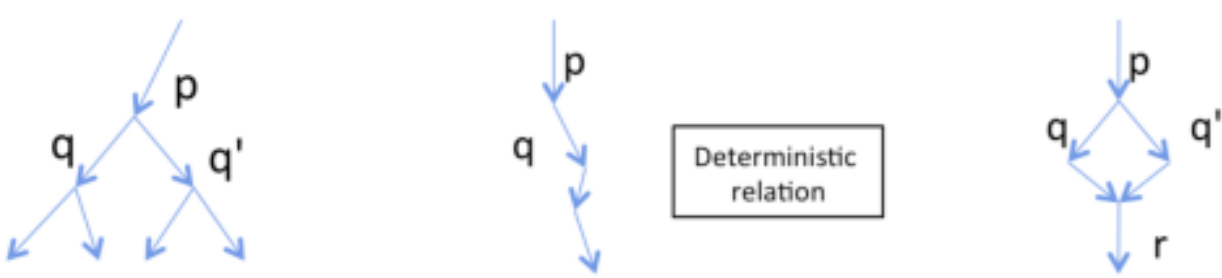

Modularity

Figure 1: Splitting condition — left: constraints that follow the splitting condition; middle: a deterministic constraint $\mathrm{p}$ (non-splitting knowledge base); right: $\mathrm{q}$ and q' are interchangeable modules (non-splitting knowledge base)

As a consequence, generic generativity can be obtained only with a knowledge structure without determinism and modularity. Conversely, a knowledge structure with determinism and modularity prevents generic generativity. Hence, this formal model provides us with a clear hypothesis with which to analyse creative design:

\section{knowledge base.}

H2: creative designers (aiming at generic generativity) will rely on a splitting

Conversely, in the case of non-generic generativity, the designer relies on a nonsplitting knowledge base.

\section{Condition 2: countable condition (sufficient condition)}

How can one build a generic filter? There is no single way. However, there is an interesting sufficient condition: if $M$ is countable, then the collection of dense subsets of $M$ is countable and there exists a generic filter on $Q$ (in fact, there exists a generic filter $G$ for every $p^{*}$ of $Q$ such that $p^{*}$ in is $\left.G\right)^{4}$.

This second condition corresponds to a constructive procedure that creates a generic filter. Because the dense subsets of $M$ are countable, they can be ordered $D_{1}, D_{2} \ldots$ Beginning at constraint $p_{0}$, the designer can always find a constraint in $D_{1}$ that refines $p_{0}$ (because $D_{1}$ is dense); he or she takes $p_{1}$ and can then always find a constraint $p_{2}$ in $D_{2}$ that refines $p_{1}$ (because $D_{2}$ is dense), and so on. The sequence of constraints creates a generic filter $G$. If the knowledge base initially met the splitting condition, then the filter is not in M. This means that the design process is determined by the dense subsets and the countability logic that allows the classification of the dense subsets.

By contrast, what is the design process associated with a knowledge structure that does not meet the splitting condition? It can be shown that the generic filter is determined by the conditions where there is determinism and modularity ${ }^{5}$. The design process in the

\footnotetext{
${ }^{4}$ Demonstration (see (Jech 2002), p. 203): Let $D_{1}, D_{2} \ldots$ be the dense subsets of $Q$. Let $p_{0}=p^{*}$, a constraint in $Q$. For each $n$, let $p_{n}$ be such that $p_{n}<p_{n-1}$ and $p_{n}$ is in $D_{n}$. The set $G=\{q \in P / q$ $>p_{n}$ for some $\left.n \in N\right\}$ is then a generic filter acting on $Q$ and $p^{*}$ is in $G$.

${ }^{5}$ Demonstration: If $Q$ is non-splitting, then there exists $p_{0}$ such that whatever $q$ and $q$ ' are refining $p_{0}$, there is $r$ such that $r<q$ and $r<q^{\prime}$. We show that if $p_{0}$ is in $G$, then $G$ refines all conditions stronger than $p_{0}$. We want to show that, whatever $q<p_{0}$, there is $r$ in $G$ that refines $q$. To this end, we introduce $D_{q}=\left\{p\right.$ in $Q / p$ is not refined by $p_{0}$ or $\left.p<q\right\}$. $D_{q}$ is dense: for every $p$ in $Q$, either $p$ is not refined by $p_{0}$ and it is in $D q$ or $p<p_{0}$; we know that $q<p_{0}$ and $Q$ is non-splitting, and hence, there is $r<p$ and $r<q$. $D_{q}$ is therefore dense. $G$ therefore intersects $D_{q}$. Hence, for every $q$ that refines $p_{0}$, there is an $r$ in $D_{q}$. Moreover, we know that $p_{0}$ is in $G$, and hence, $r$ in $D_{q}$ necessarily refines $p_{0}$. Therefore, every constraint stronger than
} 
case of non-splitting conditions is not determined by the dense subsets but is structured by the constraints where the knowledge base is non-splitting; i.e., where determinism and modularity begin. One would then expect a design process based on constraints (deterministic or modular) in non-generic generativity and a process based on dense subsets in generic generativity.

Hence, the formal model provides a clear hypothesis with which to analyse creative design:

H3: creative designers (aiming at generic generativity) can follow a design process defined by the order of the dense subsets.

Conversely, in non-generic generativity, design will rely on constraints that are modular or deterministic.

\section{Part 2: Research questions and method}

\section{Research questions}

In brief, based on formal models of design like forcing, we formulate the following research hypotheses regarding creative design.

$\mathrm{H} 1$ : creative design aims at generic generativity; i.e., the design of an entity that is not in the initial knowledge base and that requires the reordering of the knowledge base by including all combinations of the newly designed entity and the previously known entities.

$\mathrm{H} 2$ : creative design relies on a splitting knowledge base to get generic generativity; hence, learning creative design should involve gaining the ability to create a splitting knowledge base.

H3: the creative design process can follow a design process defined by the order of the dense subsets; hence, learning creative design should involve ordering dense subsets.

Said differently, formal design theory predicts that there are conditions that need to be met to realize generic generativity. This is intriguing. To check these conditions, it is interesting to analyse expert designers who are famous for their generativity, so as to check that their generativity can be considered a form of generic generativity, and then to analyse whether their knowledge base meets the conditions predicted by formal design theory.

\section{Methods-material and analytical framework}

To empirically study generic generativity and its conditions, we need an empirical situation where generic generativity is most likely (to check $\mathrm{H} 1$ ) and we need to be able to characterize the knowledge base of the designer. This second condition is particularly hard to meet; i.e., how can one access the designer's knowledge base? Our research method involves studying courses offered at design schools. The study of courses provides direct

$\mathrm{p}_{0}$ is refined by a constraint in $\mathrm{G}$. Hence, every constraint stronger than $\mathrm{p}_{\underline{0}}$ is in $\mathrm{G}$. Hence, $\mathrm{G}$ is determined by $p_{0}$. Note that the splitting condition is sufficient but not necessary. A nonsplitting knowledge base $Q$ can be used to create a generic filter $G$ not in $M$, which is a consequence of the theorem above that states that G must "avoid" all $p_{0}$ where modularity or determinism begins. 
access to the knowledge acquired by the designer at school and hence, specifically, the knowledge structure built to do his/her designer task.

We focus on courses offered at Bauhaus for two reasons. 1) Bauhaus is famous for its powerful generativity. Although it requires further investigation, there is a good chance that $\mathrm{H} 1$ holds true for Bauhaus designers. 2) Bauhaus is famous for its formal teaching, which provides us with an impressive corpus with which to study the knowledge structure and design processes invented by famous professors to meet the challenge of creative design.

\section{Material: Itten and Klee courses}

This paper does not address all aspects of Bauhaus teaching but focuses on the courses given by Klee and Itten. This corpus, often criticized to be too formal and 'scientific' to meet generativity challenges, will nevertheless provide strong elements for our research.

Itten (1888-1967) was invited by Walter Gropius to teach an introductory course at Bauhaus. Itten taught this course from 1919 to 1922 (i.e., the very first years of Bauhaus). He considered that 'imagination and creative ability must first of all be liberated and strengthened' and he proposed to do this by providing specific knowledge on the 'objective laws of form and colour', with the idea that it would 'help to strengthen a person's powers and to expand his creative gift' (Itten 1975). His theory of contrast had to 'open a new world to students'. His famous theory of colours intended to 'liberate the study of colours harmony from associations with forms' and to help discover 'expressive quality of the colours contrasts' (Itten 1961). Hence, this course will be particularly helpful for our study of the kind of knowledge structure that can improve generic generativity.

We can go one step further to sharpen our analysis. It is interesting to note that the idea of providing knowledge to improve design capability was not new. Vitruvius had already (in the first century) insisted on the necessity for architects to master a large corpus of knowledge (Vitruvius 1999). When Itten taught his courses, engineers in Germany learnt engineering design by learning machine elements and engineering sciences (Heymann 2005). Still, machine elements or engineering sciences are not necessarily seen as sources of generativity. What is the difference between the kind of knowledge and learning capacities as taught by Itten and the machine elements and engineering sciences as taught in German machine construction courses at the same time?

Klee (1879-1940) was invited by Itten and Gropius in 1921 to teach at Bauhaus, where he remained as a professor for 10 years. His course 'Contribution to a pictorial theory of form' is described by Herbert Read as 'the most complete presentation of the principles of design ever made by a modern artist' (p. 186) (Read 1959). As he explains in the retrospective of his course (lesson 10), 'any work is never a work that is, it is first of all a genesis, a work that becomes. Any work begins somewhere close to the motive and grows beyond the organs to become an organism. Construction, our goal here, is not beforehand but is developed from internal or external motives to become a whole' (Klee 2005) [our translation]. His intention is hence to teach a process that creates an organism, a whole, which unfolds step by step. With Klee, it is particularly relevant to study design processes leading to generic generativity.

Here again we can go one step further. We know of such design processes that ensure that a coherent whole will emerge step by step. For instance, systematic design(Pahl et al. 2007) prescribes to develop a product through four main steps (i.e., functional requirements, then conceptual design, embodiment design and detailed design). Again, such a process is not particularly well known for its creative aspects, or more precisely, its 
capacity to break design rules. Hence, what is the difference between the Klee design process and a classical engineering design process?

\section{Sources}

To study the courses, we rely on primary sources (Gropius 1923, 1925; Itten 1975, 1961; Kandinsky 1975; Klee 1922, 2005, 1966) and secondary sources (Wick 2000; Whitford 1984; Droste 2002; Schwartz 1996; Campbell 1978; Friedewald 2011). Note that the quality of primary sources is excellent. In particular, Klee said he was stressed by teaching so he wrote in his notebooks all the details of his courses, including sketches made during courses.

\section{Analytical framework}

In each case, we first present the courses, as described by the teacher and confirmed by former students. We then analyse the design logic in teaching from two perspectives: i) how does the teaching process affect (or attempt to affect) the knowledge structure of the students, and can this knowledge structure be related to the splitting condition (in particular, we will have to identify the 'constraints' for Bauhaus students, and the structure of these constraints) and ii) how does the course help the student learn a specific design process, and is this specific design process related to the countability of dense subsets? (In particular, we will identify dense subsets for Bauhaus students and analyse how they relate to each other, so that they can be considered 'countable'.)

To analyse the evolution of knowledge structures and the design process implied by design courses, we coded with C-K design theory (Hatchuel et Weil 2009)several Itten and Klee exercises. The theory provides us with an analytical framework that we can use to follow knowledge expansion resulting from design courses. In each case, we coded in $\mathrm{K}$ the knowledge acquired during the past courses, and in $C$ the terms of the exercise. We then coded the answers to the exercises (i.e., the answer given by students when available, or the answer given by the professor) and the associated knowledge examples.

\section{Part 3: H1: style creation and generic generativity at Bauhaus}

Before analysing Bauhaus courses, we first need to discuss the logic of generic generativity at Bauhaus. We show that generic generativity at Bauhaus corresponds to a logic of teaching style creation. We establish this point in two steps. First, we review works on teaching in industrial design, showing that there has long been a tension between teaching style and teaching style creation, with style creation being a form of generic generativity. We then show how Bauhaus clearly took a position in favour of teaching style creation.

\section{Tension between teaching style and teaching style creation}

When looking at aspects of the history of industrial design education, there are recurring tensions about what should be taught.

1) United States and Germany, early $20^{\text {th }}$ century. At the end of the nineteenth century, countries such as Germany and the United States decided to deeply reform their teaching of fine art, in particular as a pragmatic consequence of the World Fairs where German and American products exhibited poor quality (e.g., see the reception of German products described by Reuleaux (Reuleaux 1877) and the poor reception of American applied arts at the 1889 Paris Exposition (Jaffee 2005)). This decision corresponded also to a 
more utopian focus on 'art as an arena of social improvement' (Jaffee 2005) (p.41) and the use of applied art as a way to recreate culture and communities in an industrial era (Schwartz 1996).

The teaching of fine art was then reorganized to be more like that of the Art Institute of Chicago and its school (Jaffee 2005). Jaffee explains that the basis of the new teaching is twofold. On the one hand, a 'vigorous technical component' (e.g., ornamental design, woodcarving, frescoing, mosaicking and the use of stained glass) was added to the offering of traditional fine arts (e.g., drawing and anatomy), in a tendency to address 'all types of works of house decoration and industrial arts, including the "modern arts" of illustration and advertising'. On the other hand, the teaching tended to be based on scientific principles: 'many American educators believed that abstract laws or principles of arts existed which, once stabilized, would not only facilitate the production of art but raise it to a higher level' (Jaffee 2005) (p. 44). These principles ranged from Ross's works (Ross 1907) to develop a rational, scientific theory of the aesthetic of perception to Dow's principles of composition (Dow 1920).

For some professors like Sargent, a leading figure of design teaching at the University of Chicago Department of Arts, such a program could support the creation of new styles: 'after the war, said Sargent in 1918 (cited by Jaffee), the United States will have to depend upon its own resources more than in the past, not only for designers but also for styles of design'. These methods were rather principles for addressing a higher, well-established, scientifically grounded 'quality'. Hence, there was an ambiguity that industrial design teaching was not really addressing the creation of new styles but intended much more to teach students existing styles to enable them to improve product quality. As Jaffee concludes, the kind of teaching finally led to an extended vision of styles, as characterized in the famous book of Gardner, a former student of Sargent at University of Chicago, Art through the ages(Gardner 1936). Gardner presented a world panorama of styles, guided by the idea that 'it was the universal values in design that made it possible for art to have a history' and providing clear methods for their appreciation and understanding.

2) France, end of the $19^{\text {th }}$ century. Some decades earlier, in 1877 the old French school Ecole Gratuite de Dessin et de Mathématiques (created in 1766) was renamed Ecole des Arts Décoratifs, to signify a new logic in teaching. The new director, Louvrier de Lajolais (director from 1877 to 1906) explained that the school did not aim to teach technical skills (which were taught at another school, the Conservatoire des Arts et Métiers) or teach academic bases (which were taught at the Ecole des Beaux Arts) but aimed at educating a new generation of artists who were to master a large scope of technical knowledge (involving, for example, textile, ceramic, wood, and metal), with increased capacity to adapt to new tastes and to provide original models to industry. From this perspective, teaching has to consider interior design as a whole, with a 'style unity' that includes painting decorating as well as interior architecture, furniture, and so on (Raynaud 2004).

How is it possible to build this style unity? As explained by Froissart-Pezone (2004), since the 1870s, style unity was based on the idea that there is 'a logical relationship that links material, function and form, structure and ornament, following the courses and theories of Eugene Viollet Leduc', who taught at the school in the 1850s and was the professor who taught many school professors at the end of the $19^{\text {th }}$ century (e.g., Victor Rupricht-Robert, Eugène Train, Charles Genuys, and Hector Guimard) (Leniaud 1994). According to (Raynaud 2004; Froissart-Pezone 2004), this education program finally led, in the early 1900s and, above all, in the time following the First World War, to a large success 
in that, in this period, the Ecole des Arts Décoratifs reached a peak, embodied by the art déco style, which was a unique style with well-identified standards. Hence, the school was able to invent and teach one new style.

3) Germany, mid-20 $0^{\text {th }}$ century. Some decades later, the tension between teaching style and teaching style creation was also at the heart of the debate that occurred at Ulm Hochschule für Gestaltung (Institute for Design) between the first director Max Bill and his successor Tomas Maldonado (Betts 1998). For Maldonado, 'Bill's venerable "good form" itself becomes just another design style among many'. Here again the idea was to avoid relying on past styles. Rejecting art-based heritage, Maldonado insisted on the capacity of the designer to 'coordinate in close collaboration with a large number of specialists, the most varied requirements of product fabrication and usage' (Maldonado 1960). Teaching had to be based on system analysis and new product management. Relying on Peirce semiotics and Max Bense teachings, the curriculum intended to 'replace cultural judgement (taste, beauty, morality) with more scientific evaluation criteria' (Betts 1998) (p.79). As Betts summarizes, Bill and his colleagues tried to 'develop a critical theory of modern consumer culture untainted by Madison Avenue machinations' (p. 80), they looked for a more "ethically-based critical semiotics" to address the relationship between people and (consumable) things'. For Bense, the issue was to 'follow the lead of the modern physicist who studies the "objective world" not by analysing its objects but rather its interactive semiotics effects' ((Bense 1956) cited by (Betts 1998) p. 79). Still, this could also be interpreted as an extension of the logic of style to the interaction between the object and its environment. At the end of the 1960s, 'even the supposedly anti-aesthetic ethos of functionalism had become just another supermarket style, as the Braun design story attested' (Betts 1998). Here again the tension between style teaching and teaching style creation was a critical issue.

Interestingly, the extension from style to meaning also directly led to the famous proposition of Klaus Krippendorff, who graduated as a diplom-designer from Ulm, that 'design is making sense of things' or is a creation of meaning (Krippendorff 1989). However, the paper of Krippendorff precisely exhibits the same tension. In the first part, Krippendorff insists on the design ambition to be a capacity to create meaning, whereas in the second part (from p. 16), meaning creation is reduced to a referential of contexts (i.e., operational context, sociolinguistic context, context of genesis, and ecological context) that an engineer would consider a good list of functional requirements.

These elements give us two insights into the issue of design teaching. First, over time, there was a progressive extension from the design of objects (e.g., domestic objects and applied-art pieces) to multiple objects (e.g., trademarks, advertisements, and shop windows) and to styles and meaning (e.g., new icons, symbols, signs, new forms of interaction between objects and people and even today 'semiotic ideologies' (Keane 2003)). A similar evolution can be seen in the historiography of design (Riccini 1998). Second, teaching styles (or meaning) are a source of tension between two approaches: teaching (past and new) styles and teaching the creation of style(s).

We can now better characterize this tension. Teaching past and new styles can be characterized as teaching the values (or what engineering would call the functional requirements') of existing styles and the ways and means to acquire them (e.g., mastering drawing, composition laws, and material techniques such as woodcarving, frescoing, mosaicking, and the use of stained glass), whereas style creation (or even 'meaning creation') consists of creating an original culture that encompasses new 'objects' as well as 
new interactive receptions by people. Hence, a clear challenge for the new style is that it has to be 'significantly' original and new (i.e., removed from past styles) yet still has to be 'meaningful' to the (occasionally lay) 'user(s)', who should be able to 'make sense' of the new by relating it to the known. The new meaning is both original and strongly related to all of what is already known. The style has to be new and will affect very large types of artefacts (e.g., techniques, objects, environments, uses, individuals and social references). This is precisely a generic generativity - new on many facets and leading to revise a whole world of objects, uses, and ways of life.

\section{Teaching style creation, a challenge at the roots of Bauhaus}

The tension between teaching style and teaching style creation was at the root of Bauhaus. This was illustrated by (Schwartz 1996) in his study of the German Werkbund, the melting pot of the debates that would later shift to Bauhaus. From the 1890s onwards, the members of the Kunstgewerbe Bewegung and later the Werkbund (500 people at the Werbund creation in 1907 and 2000 in 1914, among them Hermann Muthesius, Peter Behrens, Henry Van de Velde, Richard Riemerschmid, and Werner Sombart) launched wide discussions and initiatives on German applied $\operatorname{arts}^{6}$. They rejected the use of 'historical styles' (as used in Fachverbände, professional associations) and promoted the direct involvement of artists in the production of objects of everyday life, taking into account the industrial conditions of production and trade. The works of Peter Behrens at AEG illustrate the contrast between the 'historical style' approach and the Werkbund approach (see Figure $2 \mathrm{~b}$ ). They also show that designers like Behrens not only coped with objects but with the complete environment (e.g., AEG trademarks, retail shop windows, product catalogues, and even the factory itself).

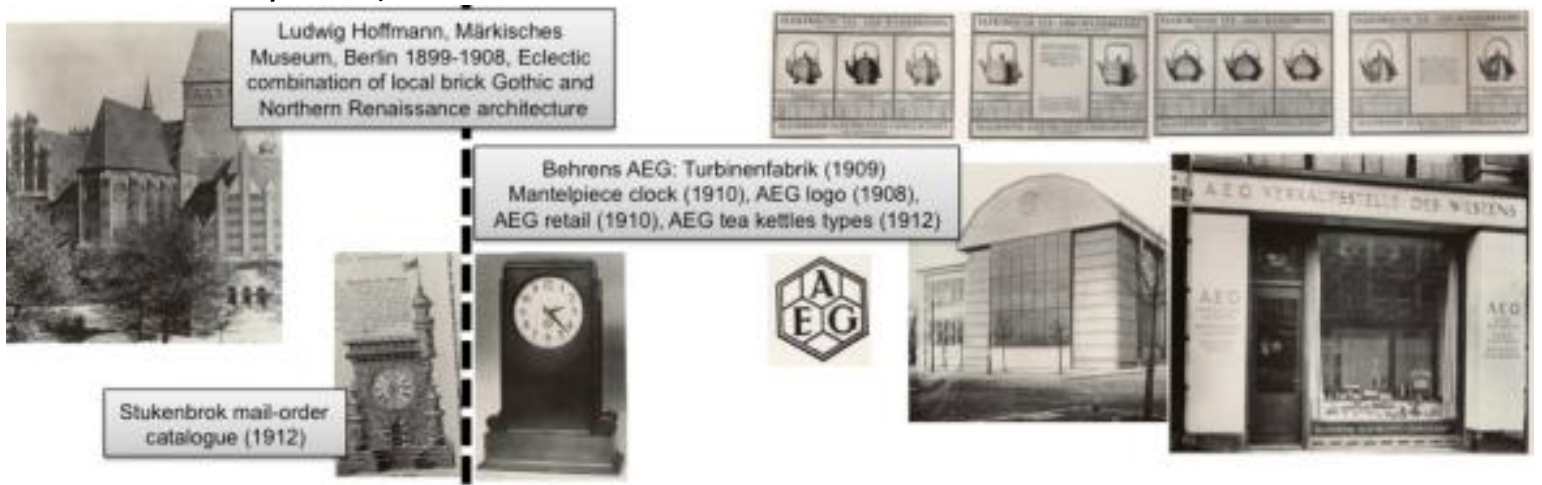

Figure 2: 'Historical styles' vs Behrens works at AEG in the 1900s-1910s. Left: one or multiple existing styles are used to design objects (a museum and a clock). Right: Behrens creates a new style coherent with many new objects (a clock, kettles, and new AEG domestic electric appliances) but also with a work environment (a factory), a retail environment (shop window) and a marketing environment (brands). (Source: adapted from (Schwartz 1996))

\footnotetext{
${ }^{6}$ They sponsored lectures, exhibitions (Köln 1914), and publications (Werkbund Jahrbücher), helped found a museum of applied arts and were involved in Dürerbund-Werkbund Genossenschaft (publishing a catalogue of exemplary mass-produced goods 1915), linked to Werkstättenbewegung (Riemerschmid, Naumann). In parallel, they made great effortsto establish a theoretical basis, and Werkbund was a forum for discussion, with a wide cultural, economic, social and political audience.
} 
As shown by Schwartz (Schwartz 1996), one of the great issues facing Werkbund was to create 'the style of our age', the so-called 'Sachlichkeit'. Sachlichkeit was not the aesthetic payoff of the functional form (and functionalism as such was widely discussed and rejected in the Werkbund) but rather the avoidance of form as Fashion (see Muthesius, 1902, Loos, the ornament as crime, 1910; and Gropius 1923). Werkbund members remembered the story of Jugendstil: Van de Velde, Riemerschmid and others proposed a new style that was finally transformed into inconsistent fashionable ornaments (see Figure 3 ). In the social tensions created by the industrial revolutions in Germany, and following Tönnies works on the new Gemeinschaft (community) that counterbalanced the complexity of contemporary Gesellschaft (society) or Sombart on Kunstgewerbe and Kultur, they wanted to organize to create a new style; i.e., a new culture and new communities created through designed objects.
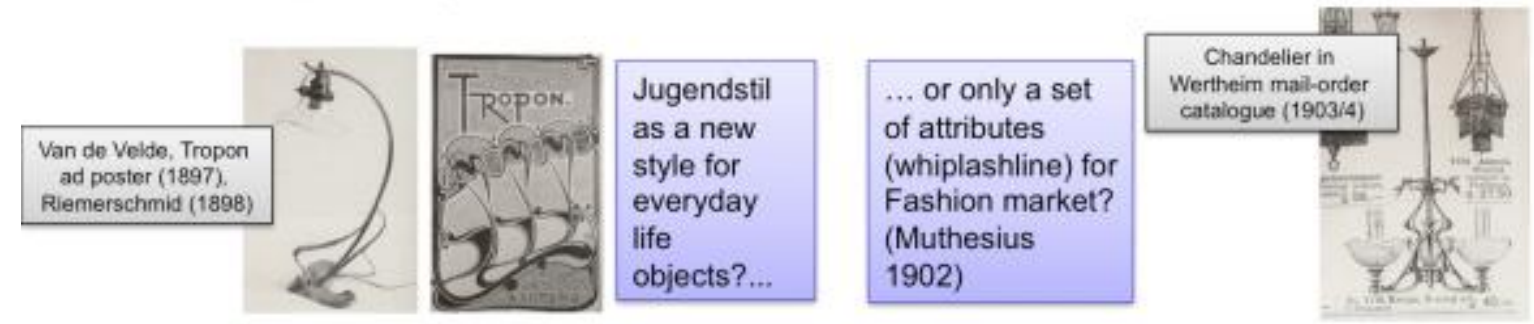

Figure 3: Jugendstil—inventing a new style (left) or just a fashionable ornament (right)? (Source: adapted from (Schwartz 1996))

Once again, this ambition was trapped by the debate between style and style creation. In 1914, the Werkbund was split between the Muthesius party of Typisierung arguing for the standardization of production and distribution of objects (protected by copyright) that would embody the new style (of the new society), and Van de Velde (supported among others by Gropius and Osthaus), who advocated a free capacity for designers to create their own 'style'.

Werkbund and the 1914 crisis laid the intellectual foundations of Bauhaus. 1) The designer should not subordinate himself to the law of any style, nor should he just make use of motifs (like the Jugendstil motifs) in designing fashionable products. 2) What has to be designed? Not a product, but a whole range of commodity products including trademarks, advertisement, shop windows, and catalogues so as to create the 'style of the age'. 3) This style creation is not reserved to a few happy designers protected by copyrights or standardized but should be made accessible to many designers through teaching.

In conclusion, we have established that Bauhaus aimed to convey to students a capacity of generic generativity. Bauhaus is thus a case in which creative design consists of generic generativity $(\mathrm{H} 1)$.

We will also verify our methodological assumption. Because teaching is considered a way to convey this generic generativity capacity, the analysis of courses is critical in testing hypothesis $\mathrm{H} 2$ and $\mathrm{H} 3$. Does the knowledge structure promoted by Bauhaus courses correspond to the structure predicted by design theory?

\section{Part 4: Results: knowledge structure and design process for generic generativity ( $\mathrm{H} 2$ and $\mathrm{H3}$ )}

We now present the results of analysis of the Bauhaus courses. We analyse first the Itten course and then the Klee course. For each course, we give a brief description and analyse the 
course according to design theory and present the results for $\mathrm{H} 2$ and $\mathrm{H} 3$ hypotheses. Finally, we underline the differences between the two courses and apparently similar courses in engineering design.

\section{Itten: a 'contrast'-based knowledge structure that better opens holes}

\section{Brief description of the Itten course}

The Itten course is based on means of classical expression and has a chapter on each of lines and points, form, colour, material, and texture.

We focus on the chapter on texture as an example and analyse the series of exercises proposed by Itten to learn about textures (Itten 1975). In a first phase, students are told to draw a lemon. Beginning with the representation of an object, Itten wants the students to go from 'the geometrical problems of form' to the 'essence of the lemon in the drawing.' This is an 'unfixing' exercise, helping the students to avoid assimilating the object with a geometrical form.

In a second phase, the students are asked to touch several types of textures, to 'improve their tactile assessment, their sense of touch.' This is a learning phase in which students 'sharpen observation and enhance perception.' (Itten 1975)

In a third phase, students build 'texture montages in contrasting materials' (see figure 4). During this exercise, students begin to use textures as a means of design. The constraint (design only by contrasting textures) helps students learn about textures (i.e., to explore the contrasting dimensions of different textures and to improve their ability to distinguish between them). It also means that students are able to explore the intrinsic generative power of textures; i.e., the superimposition of textures that should create something new, such as 'roughly smooth', 'gaseous fibrous', 'dull shiny', and 'transparent opaque'. Moreover, students begin to learn the relationship between texture and a complete work, a composition, in contrast to the idea that texture could be secondary and 'optional', chosen independently of the rest of the piece. The exercise thus makes textures a critical part determining the whole.

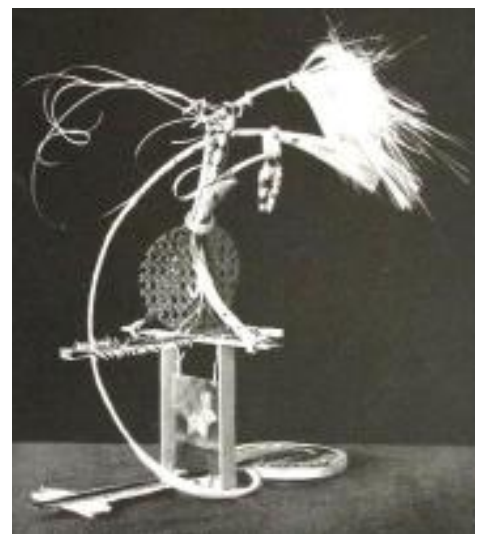

Figure 4: Texture montage exercise (source: (Itten 1975))

The fourth phase could be qualified as 'research'. As the students are by then more sensitive to the variety of attributes of a texture, they can 'go out' to find 'rare textures in plants.' It is interesting to underline that Itten does not begin with this phase. He begins by strengthening the students' capacity to recognize new things, just as a botanical researcher has first to learn the plant classification system and to discriminate features before being able to identify a new specimen. In particular, students are told to find new textures for a given material (see the figure 5 in which all textures are made from the same wood). Once 
again, this is an exercise of disentangling texture from other fixing facets (i.e., materials in this case). Note that, in this step, Itten does not teach a pre-formatted catalogue of textures but teaches the student how to learn textures, thereby building their personal 'palette'.

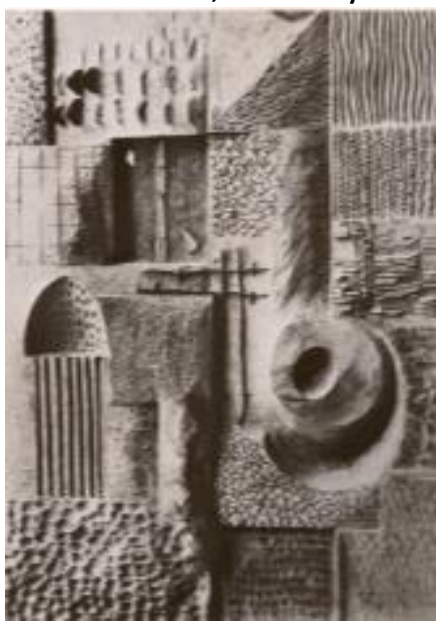

Figure 5: Several textures of the same material (source: (Itten 1975))

The fifth phase consists of representing textures. Itten stipulates that students have to represent 'by heart', 'from their personal sensation', to go from 'imitation' to 'interpretation'. Instead of being an exercise of objective 'representation', this exercise is intended as a design exercise, as students had to combine textures with their own personality. Just as phase 4 aims at creating something new from the superimposition of contrasting textures, the idea in this phase is that the new should emerge from the superimposition of texture and the individual 'heart'. The phase is also intended to help improve sensitivity.

The sixth and final phase consists of characterizing environmental phenomena as textures. For instance, the figure shows a marketplace painted as a patchwork blanket. Itten urges students to use texture as an autonomous means of expression and not to just produce a 'constrained' ornament. By combining their enriched algebra of textures and the algebra of scenes, students can create new 'textured scenes' that are more than the scenes and more than the textures. As Itten (Itten 1975) explains, 'It stimulates the students to detach themselves from the natural subject, and search for and reproduce new formal relations'.

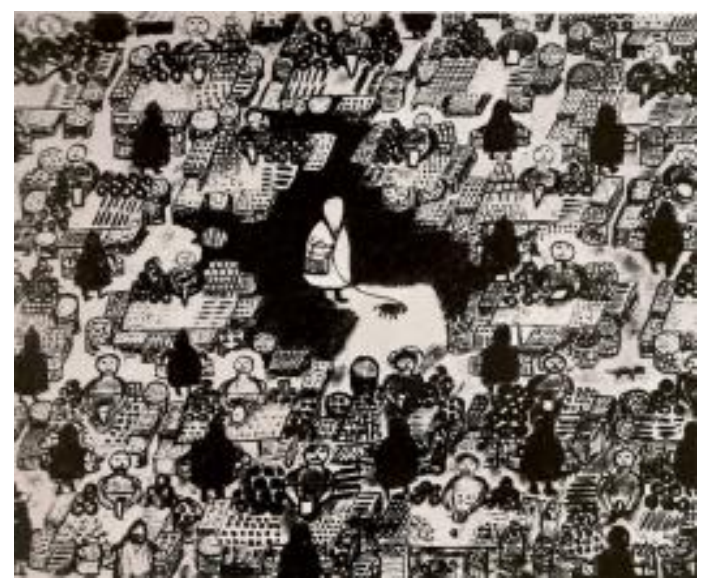

Figure 6: Characterization of environmental phenomena as textures (source: (Itten 1975)) 
We could repeat this analysis for other aspects of Itten's teaching (e.g., lines and points, form, and colour).

\section{Analysis of the Itten course from a design perspective}

We now turn to the analysis of the Itten course. We first need to underline one critical point: Itten does not teach a stabilized knowledge base (or a stabilized style associated to it) but rather teaches students how to build their own knowledge base (to create their own style). In all cases, one finds that Itten improves three facets of his students design capabilities.

a- Self-evidently students extend their knowledge base for the notion of interest (e.g., texture), knowing more about (texture) materials, (texture) descriptive languages, (texture) perception, and (texture) building techniques. In terms of colour, Itten teaches to increase the student's capacity to perceive 'distinct differences between two compared effects' and to 'intensify or weaken (colour) effects by contrast'. In that sense, there is no great difference from an engineer learning machine elements, their production processes, and their functionalities; i.e., learning what design theorists would call design parameters and functional requirements. In both cases, seen from this perspective, the knowledge structure appears as a well-ordered catalogue of recipes. Still, the knowledge structure is a highly complex one, for which only a few combinations have been explored.

b- Students are ready to learn about the notion of interest. They know parts of what they don't know: the contrasts, the materials, the process, the perception and sensations they have tried to convey and those they could not try to convey involving unavailable materials, new combinations, and sharper sensations. As Itten writes, 'a theory of harmony does not tend to fetter the imagination but on the contrary provides a guide to discovery of new and different means of colour expression' (Itten 1961). The industrial design students know the limit of what they know and the way to learn beyond. They not only know the state of the (their) art but also the state of the non (yet) art. The knowledge structure is closer to that of a very smart scientist-engineer, who not only knows the engineering sciences but also know their limits and is ready to follow the advances they make.

At this point, we can already underline that this knowledge structure enables a designer to extend his or her own design rules. It is closer to style creation than teaching the design parameters and functional requirements of pre-given styles.

c- Beyond rules and the learning of rules, students are able to deal originally with briefs or to give themselves original briefs. This is the key logic of contrasts. Itten does not teach colours, forms, and textures but teaches the contrast between colours, forms, and textures. The juxtaposition provokes surprise, it creates 'holes' in the knowledge base, which have to be explored by the designer. A contrast does not correspond to a unique meaning with a one-to-one correspondence but instead paves the way to multiple elaborations. With Itten, students learn to formulate exercises (briefs) that can be oriented to explore new textures, new texture montages, and new texture contrasts. These briefs can also be oriented towards creating original works using textures (or colours or forms) in a unique way. In that sense, the teaching of Itten is much closer to educating a senior scientist, who has not only to answer exogenous research questions but has also to be able to construct his or her own, original, research program. 
Up to this point, we understand that Itten's teaching is sophisticated, much more than just teaching the elements of an existing style or teaching a new technique or relying on a kind of 'project-based learning'. We have now to clarify how this kind of teaching can help deal with generic generativity.

It should first be noted that, despite apparent knowledge expansion, the knowledge base relies on classical motives (e.g., drawing, colour, material, and texture). Therefore, if there is generativity, it is not based on the use of radically new means. At the time, there were transformations in expression means, and Bauhaus was aware of them. For instance, photography was considered an applied art, as evidenced by a book published by Meurer (Meurer 1896) and photographs published by Karl Blossfeldt (Stoots 2011; Blossfeldt et Nierendorf 1928). Bauhaus participated in this movement through the teachings and book of Moholy Nagy (Moholy-Nagy 1938). Bauhaus is also famous for the works done on new typography. However, Itten did not teach these new means and relied on a known set of means (e.g., textures and colours). Hence generativity won't come from new means but from the combination of known means.. Still, a combination is not necessarily creative and does not necessarily imply $\mathrm{H} 2$, that a knowledge base should meet the splitting condition. We therefore ask, how does the knowledge base enabled by the Itten course meet the splitting condition? To this end, we made an in-depth analysis of the design reasoning in Itten's exercises, to analyse how they lead to changes in the knowledge base of the students. We illustrate this analysis for one case, taken from the texture lesson (see figure 7).

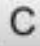

Phase 3: texture montages of contrasting materials, bound by rythmic forms

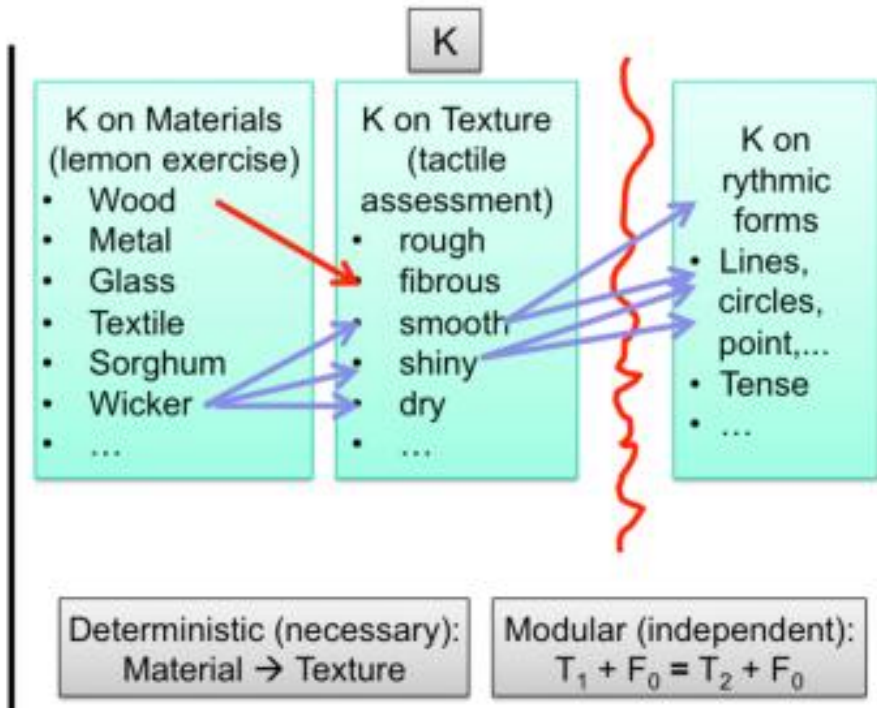

Figure 7: C-K analysis of one Itten exercise ('texture montage') —initial state

The exercise brief is given in C: 'texture montages of contrasting materials, bound by rhythmic forms'. In $\mathrm{K}$, there is the knowledge acquired by students during the first courses, related to Itten's exercise: knowledge about materials, textures, and rhythmic forms. 


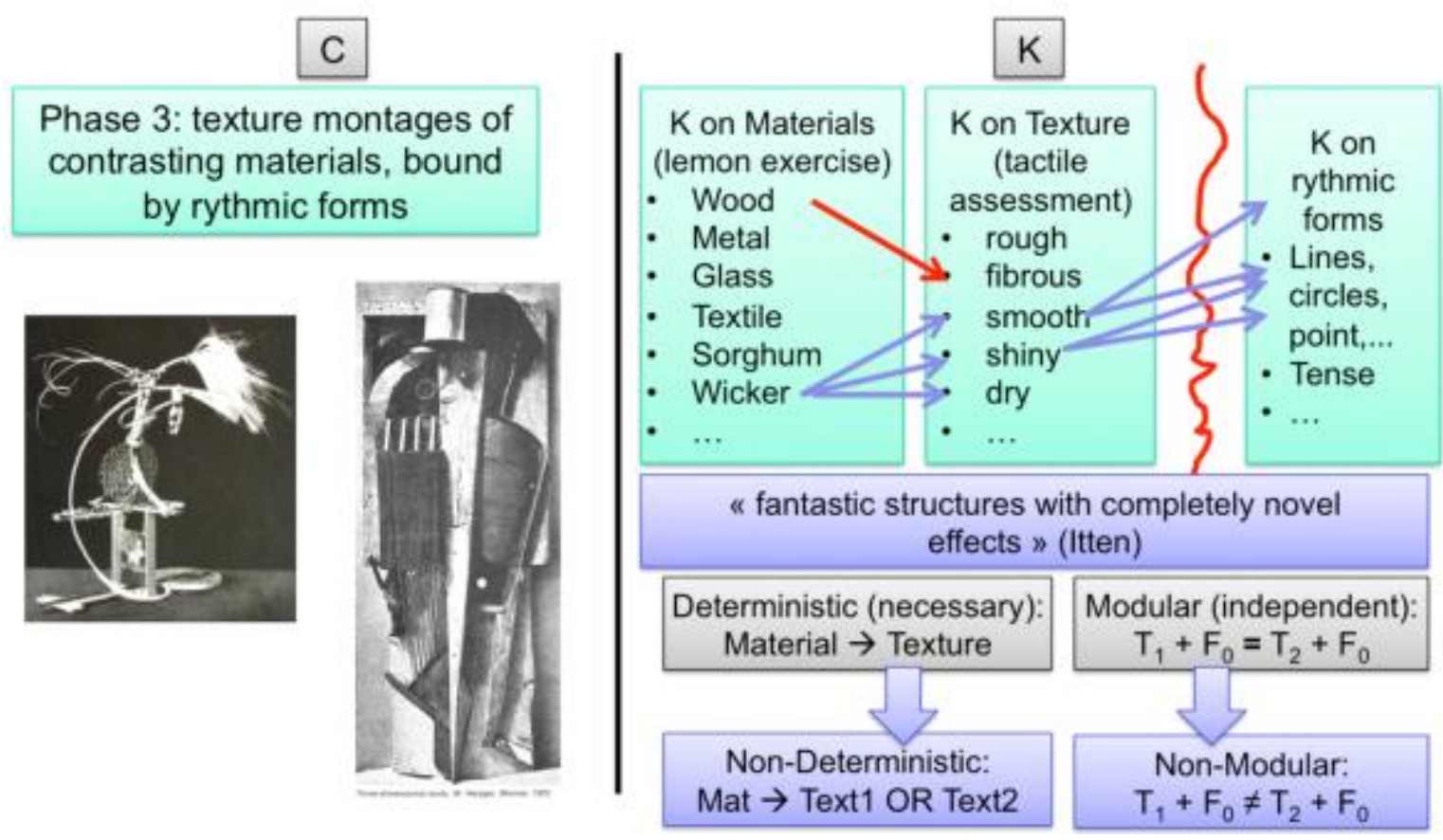

Figure 8: C-K analysis of one Itten exercise ('texture montage')—final state (sources for the pictures:

(Max Bronstein 1921))

According to Itten, the exercise leads to 'fantastic structures with completely novel effects' (see two examples in the figure above), and hence a form of generativity ('fantastic') that might be said to be generic in the sense that it is not the structure but the 'effects' that are new. The exercise creates new effects and not only a new structure.

The consequence of the exercise on student's knowledge is summarized in $\mathrm{K}$ in the figure above. In this particular case, the expressions means (which correspond to the language of constraints in forcing) are unchanged. The exercise uses knowledge on materials, texture and forms gathered in the previous exercises (i.e., the lemon exercise, tactile assessment exercise and montage lesson). However, the structure of the relationship among them (which corresponds to the partial order of constraints in forcing) has strongly evolved. In the initial state, the relationship between material and texture is deterministic; e.g., wood implies fibrous texture. Additionally, the relationship between texture and form is modular, in that whatever the form, it is possible to add texture 1 or texture 2 without there being major changes to the final result. After the exercise, these two properties are changed. In the example, the material 'wicker' is related to shiny, smooth, and dry properties. Hence, the deterministic law is relaxed. Meanwhile, the form is made of and by textures, and it appears that there are new relationships between some textures and some form properties. A texture will reinforce slenderness or lightness or angularity. Therefore, a form with texture 1 will now differ from a form with texture 2 .

In this particular case, one exercise leads to the revision of the relationship between expression means (i.e., a partial order of constraints), resulting in two specific properties of the knowledge base: non-determinism and non-modularity. C-K analysis of the other exercises confirms this transformation. The knowledge structure built through Itten teaching can be characterized by two properties.

Non-determinism: when confronted by a concept, the student cannot use a deterministic law. Because of the variety of contrasts, there is no law that links one colour to one material to one texture to one effect. At each step, the designer can 
always explore multiple paths. Itten fights against 'laws of harmony' or 'clichés' that tend to impose relations (e.g., warm fibrous wood or cold smooth shiny metal). He wrote in his book on colours that we should 'liberate the study of colours' harmony from associations with forms.' For instance, the 'cliché' deterministically associates wood with a fibrous property, while Itten's teaching opens the way to smooth wood, which will differentiate the designer's work from all previous work using wood as a fibrous material.

- $\quad$ Non-independence: not all attributes and not all combinations are equivalent. Itten does not advocate relativism. On the contrary, he states that 'subjective taste cannot suffice to all colour problems'. Relativism deletes the valued differences. If texture is only a 'secondary', 'modular' property, then all works with wood are similar; i.e., a work with smooth wood is indistinguishable from a work with fibrous wood. Against 'relativism', Itten teaches that one does not add a texture independently of the other aspects; if a scene or montage can be made of and by texture, then a scene or a sculpture is not 'insensitive' to the choice of texture. For Itten, each attribute (e.g., texture, colour, or material) affects the whole work and propagates to all other aspects. Here again, the notion of contrast is critical in that each juxtaposition is a source of meaningful contrast that has to be amplified, tamed, or counterbalanced by another.

In concluding Itten's teaching, we state that non-determinism and non-independence are two critical properties of the knowledge structure provided by Itten.

As a consequence, $\mathrm{H} 2$ is confirmed for the Itten course-a splitting knowledge base is a condition for generic generativity.

\section{Comment on the Itten course: similarities and differences with engineering design approaches}

Let's underline that the two properties stated above are much different from the logic of classical engineering design. Formally, we can associate the knowledge of expression means to machine elements (Kesselring 1942; Pahl et al. 2007; Reuleaux et Moll 1862; Bach 1896, 1924; Findeneisen 1950; Laudien 1931; Rötscher 1927) (these are 'constraints'); we can say that engineering design consists of combining machine elements just as industrial design consists of combining expression means, and we can associate the knowledge of the laws of contrast to engineering science (Rodenacker 1970; Hubka et Eder 1988; Dorst et Vermaas 2005), in the sense that some laws determine the design parameters to be used.

This comparison reveals strong differences in the structure of constraints.

1) Modularity: we have seen that Itten teaches the student to combine expression means in a non-modular way, with each expression means being in strong relationship with all previous means, amplifying and expanding them. By contrast, in engineering design, machine elements are made to be modular. For instance, machine elements that have to meet a similar set of requirements are substitutable; or it is possible to use one machine element for one functional domain, independently of the type of object or the type of user. As soon as there is a rotating rod, it is possible to use a ball bearing, be it for a car or a power plant.

2) Determinism: Itten teaches the laws of contrasts and the laws of colours, with the idea to show that there is no determinism and that there is a multiplicity of possibilities - there are seven types of contrasts and no rule that links colours in one single way. By contrast, engineering design tends to use laws to determine 
design parameters. Employing scientific laws, it possible to use the set of requirements to determine the technology to be used. Ideally, it is expected that knowledge of engineering science will be rich and precise enough to immediately determine one object for each list of requirements.

These two contrasting structures of knowledge lead to contrasting forms of generativity. There is generativity in engineering (Lindemann 2010) that consists of, for instance, finding a new technique with which to address previously unmet requirements (e.g., energy harvesting in microelectronics would benefit from using energy dissipated by microprocessors). This generativity improves some aspects of the final design but keeps the others unchanged (e.g., the microprocessor with energy harvesting is a microprocessor that has one additional property in that, for instance, it still computes). It follows a modular logic and the knowledge base of the engineering designer remains non-splitting. As a consequence, the new object will be immediately compatible with other objects, without requiring the redesign of a whole set of entities.

By contrast, Itten's teaching enables students to build a splitting knowledge base. The newly designed entity will hence intersect all types of attributes. In the texture exercise, the creative effort finally implies material attributes (e.g., wood or wicker), texture attributes and form attributes. The newly designed entity paves the way to the redesign of complete sets of entities. Creating a new style, all existing objects could be redesigned with this new style.

Of course, as we will discuss in the conclusion, one can certainly find today design that is made by engineering and that is still generically creative, and conversely, we can certainly find design made by industrial designers that is not generically creative. Our result is not at the level of the professions but at the level of the structure of the knowledge base conveyed by Itten teaching and by machine elements and engineering science teaching.

In summary, Itten teaches students how to build their own knowledge base meeting the splitting condition (i.e., non-determinism and non-modularity). By contrast, classical engineering design enables students to build a knowledge base that is non-splitting.

\section{B- Klee: composition as a genesis process, leading to out-of-the-box design}

\section{Brief description of the Klee course}

We now study the Klee courses. We present three facets of the courses.

1- Even more so than Itten, Klee provides an extended language of the design object. Beginning with 'lines', Klee introduces the notions of the active (vs passive) line, free line, and line 'with a delay' (befristet in German) (see figure 9). After lines, Klee addresses notions such as the rhythm of a piece, the spine of the piece, the piece as a weighing scale, the form as movement, the kinetic equilibrium, the organs and the organism. In particular, Klee proposes new languages for perception, considered as a 'moved form' with specific kinetics, ranging from pasturage to predation (see figure 10). 


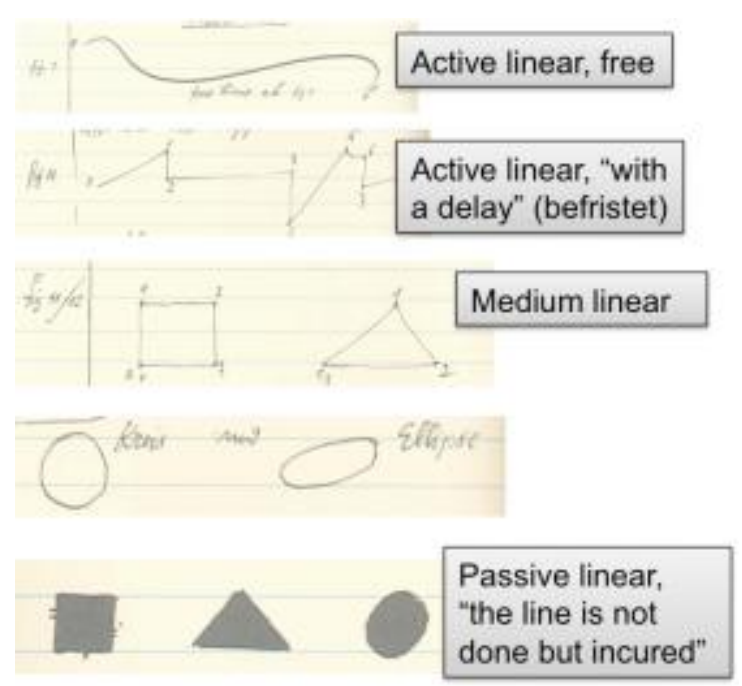

Figure 9: A new language for lines (source: (Klee 2005))
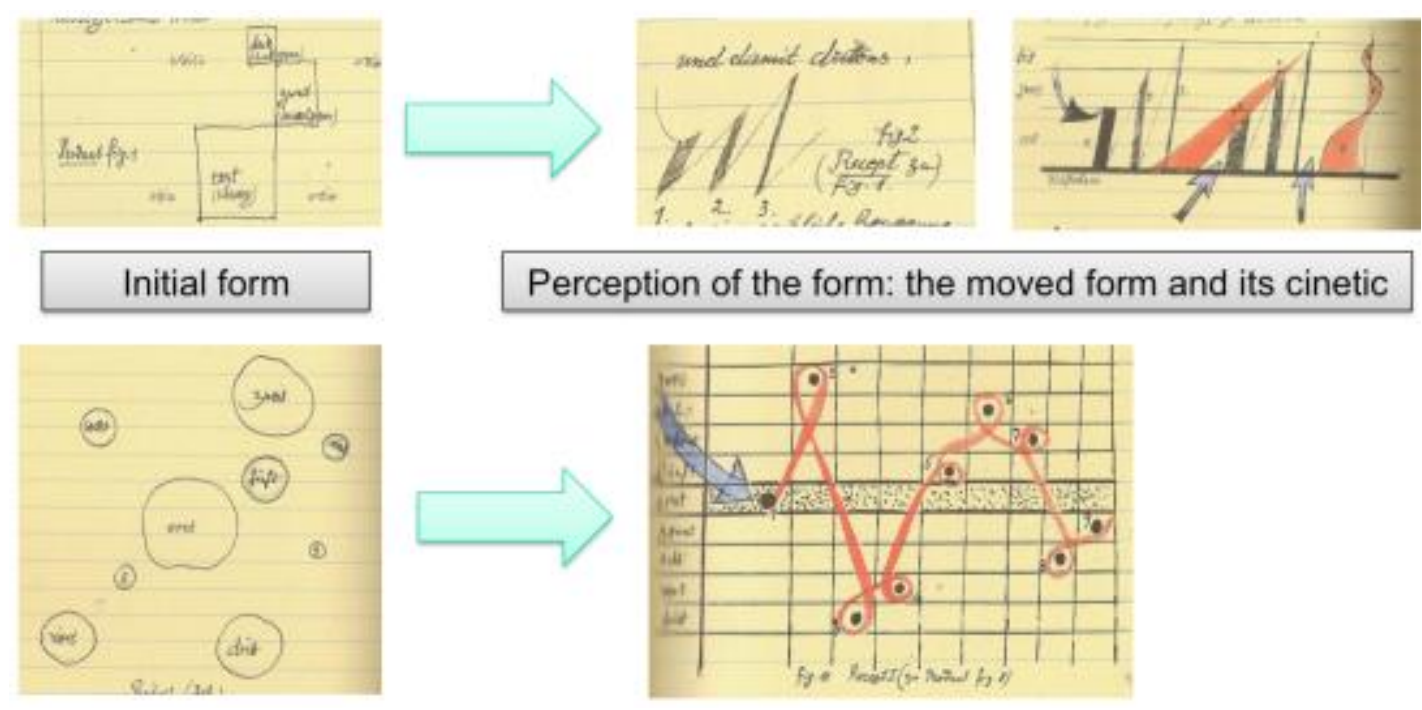

Perception of the form: the moved form and its cinetic

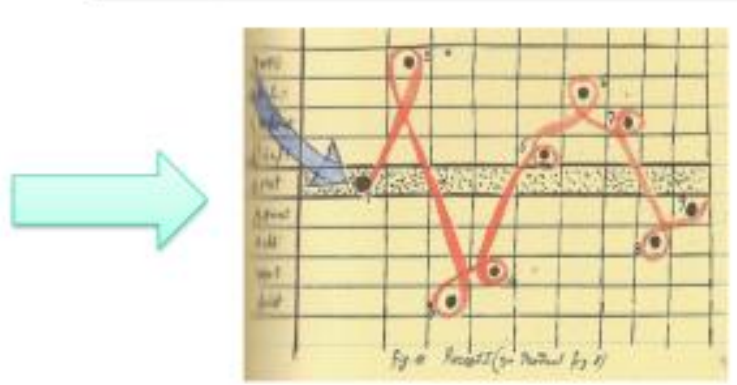

Figure 10: A language of perception: pasturage and predation; the kinetics of the moved form (source: adapted from (Klee 2005))

2- Each chapter of Klee's teaching not only investigates one dimension of the work (as did Itten for lines, surfaces, colour, textures, and so on) but discusses how one 'part' relates to the 'whole'. For instance, the 'line' is related to the 'perspective' of the whole piece, the 'weight' of each element is related to the 'balance' of the whole piece, the 'elemental structural rhythms' of the piece are related to the 'individual' that integrates all these rhythms, the 'joints' between elements are related to the 'whole organism', and the 'moved forms' are related to the 'kinetic equilibrium' of the received piece. This part-whole logic leads to a renewed logic of composition. In several exercises, Klee teaches composition. See the figures 11-12 for examples. Note that the composition criteria are not 'external' or stable evaluation criteria. They are enriched by the work. See, for instance, the example of 'balance' (figure 12). Klee considers that the 'balance' is a composition criterion, represented by the vertical cross (i.e., a balance with a vertical column and a beam). The superimposition of imbalanced situations creates a balance but this balance is not the initial vertical one but a 'cross-like' balance. The composition criteria create dense subsets of constraints. They are 'dense' in the sense that each composition has a balance (and 
can thus help characterize all possible objects). This balance is obtained through different forms of expression means (constraints).

\section{Exercise: an organism with 1) active organ (brain) ; 2) intermediary organ (muscle); 3) passive organe (bone, weight)}

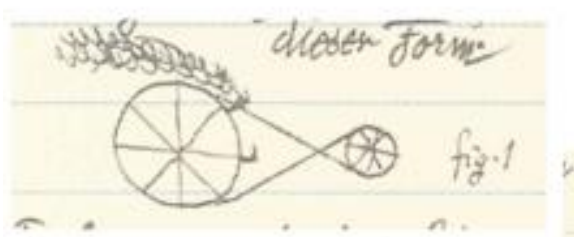

Student proposal: a hydraulic wheel

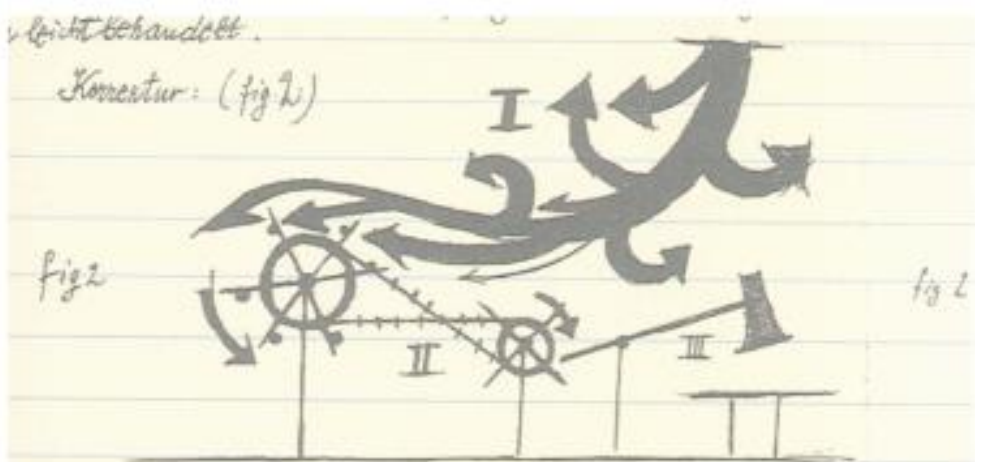

Figure 11: Composition of a piece with three organs—-discussion of a hydraulic wheel schema proposed by one student (left) (source: adapted from (Klee 2005))

Klee supports the idea that a hydraulic wheel can be represented by these three organs and his drawing insists on the composition of these three organs (right). He explains changes to the drawing (right) in that the principal organ - the water - originally is drawn with an undulating structure that is a form of cliché, whereas its form should relate to its role as the main organ. He insists on 'the right choice in the relationship between the organs' ('active fall = brain; linked wheels = intermediary; hammer = passive organ'), 'the right choice in the form of the organs' ('main organ should appear in the most individual way and the others are gradually articulated downwards') and 'the right choice for emphasizing the relationship between the organs' ('main energy, intermediary energy, secondary energy').
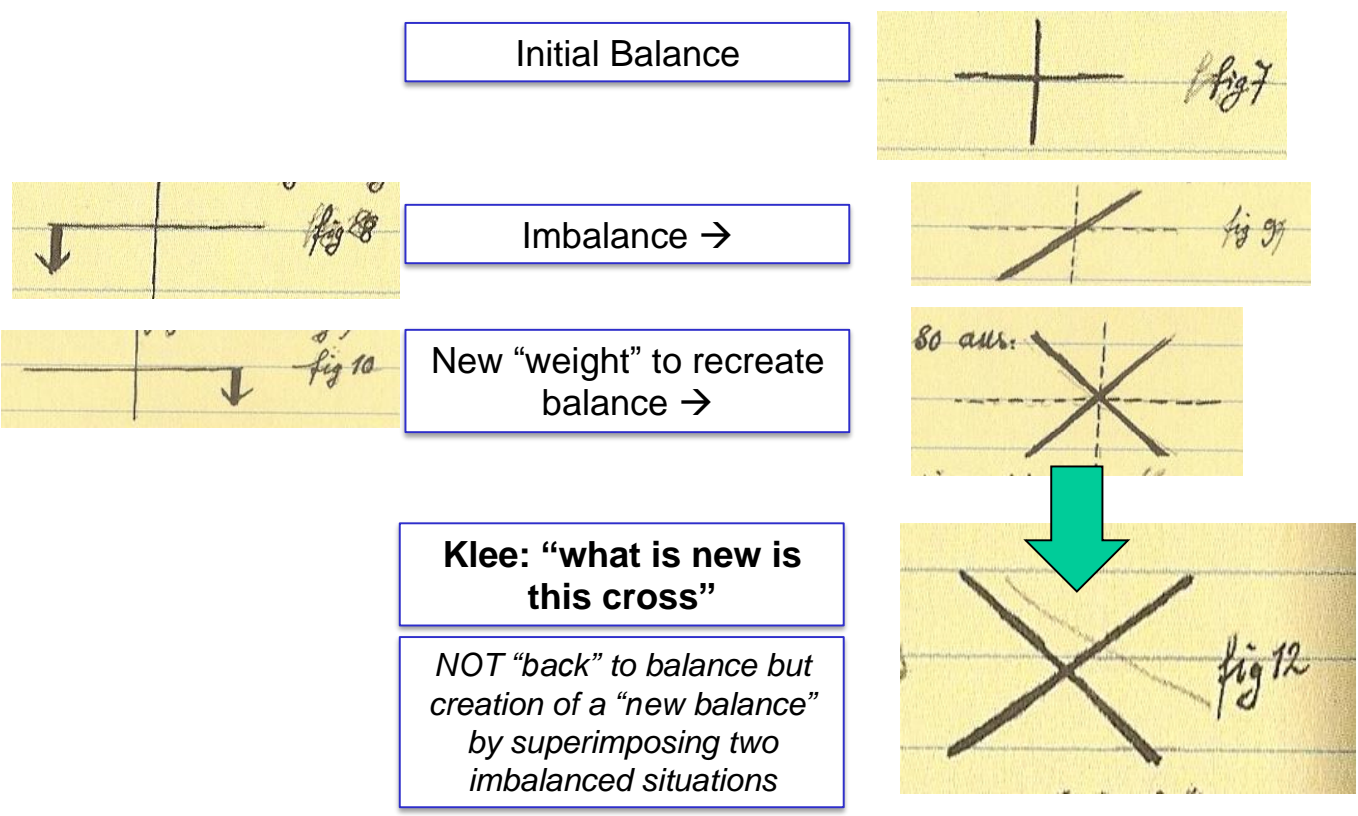

Figure 12: Working on the 'balance' composition criteria (source: adapted from (Klee 2005))

Initial situation: a 'balanced' composition, in which the balance is a scale that can be represented by a vertical cross ( horizontal line $=$ horitzontal beam of the scale and vertical line $=$ vertical rod of the scale). A new weight is then added to the composition (left), and the balance changes (right). To rebalance the composition, another 
weight is added (left); i.e., a weight is added instead of the previously mentioned unbalancing weight being removed. A new 'balance' then emerges, which is no more like a scale but is like the superimposition of two imbalanced situations; hence there is another cross. As underlined by Klee, 'what is new is the cross, we don't go back to the initial balance but we create a new balance.'

3- Klee also teaches how to shift from one aspect to another. One example is given in his second chapter. Teaching the 'weight' and balance of a piece, Klee shows that the imbalance of surfaces (see figure 13) calls for a new 'weight' to be balanced (e.g., the imbalance of surfaces is balanced by a colour). However, the introduction of coloured surfaces leads to a new imbalance. The scale thus 'oscillates' and creates rhythms in the whole. This is a shift from weight and balance to scales and rhythm, which creates the 'spine' of the piece (see figure 13). This transition is mediated through music, in which 'weights' and 'balances' correspond to rhythms, tempi and bars.

The Klee teaching structure corresponds to the presentation of transitions: from perspective to weight (via gravity), from balance to rhythm (via scales, space and music), from individual to joints (via physiology), from joined individuals to organisms and organs, and from organism to 'moved form' (from the eye's perception). Formally speaking, this corresponds to the passage from one dense subset to another, and is hence a form of 'countability'.

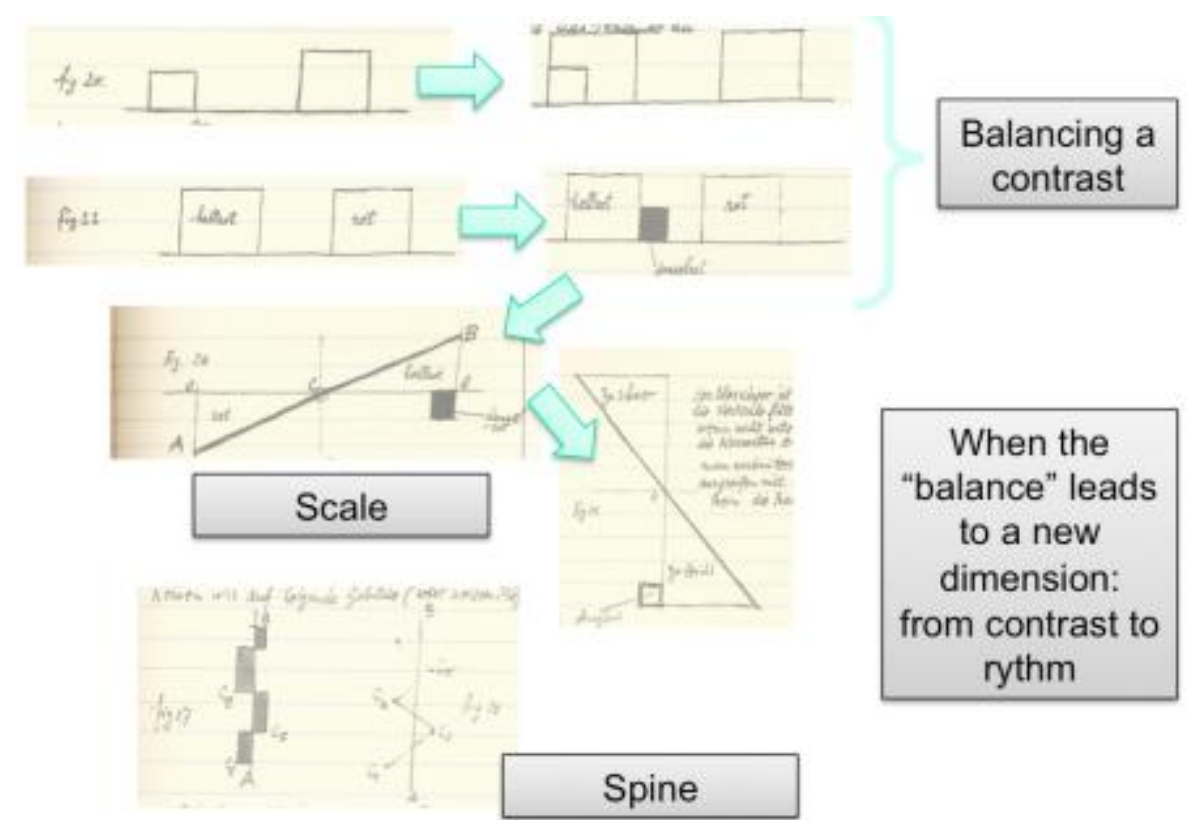

Figure 13: Shifting from one aspect to the following one- the case of balance and rhythms (source: adapted from (Klee 2005))

\section{Analysis of the Klee course from a design perspective}

How does Klee improve the design capabilities of the students? Let's first confirm that Klee's teaching can be related to teaching style creation.

To begin, let's underline that, just like Itten, Klee does not teach radically new expression means. The expression means discussed in Klee's teaching are reduced to drawing and painting (and do not even address texture, material or shape). Building on this reduced set of means, Klee rather teaches how to enrich them in that he provides students with a new language for lines, forms, motives, and 'joints'. Does Klee teach a pre-existing style? Just like Itten, Klee does not follow the usual categories of applied art teaching or 
beaux art teaching (e.g., landscape, mythological scenes, and still life). He introduces a new language with which to speak of the composition and style of a piece of art: balance, rhythm, 'organic discussion', and 'kinetic equilibrium'. This language helps the artistraise questions about how to organize an 'organic discussion' between a line and a circle, how to build an organism that combines given organs (see the waterwheel exercise above), and how to provoke a predefined 'kinetic equilibrium' (i.e., not the work 'as such' but the work as seen by the viewer ('moved forms')); i.e., how to integrate this 'moved form' into the composition of the fixed form. In all these exercises (and particularly the last example), the notion of style creation is at the heart of the teaching.

We thus confirm that Klee's courses deal with a form of generic generativity. Let's now analyse the kind of design capabilities taught by Klee to improve generic generativity. To this end, we conduct an in-depth analysis of the design reasoning in Klee's exercises. We illustrate this analysis for one case, taken from the lesson on joints and composition of an individual with structural motives.

\section{C}

"a composition with rigid and loose joints"

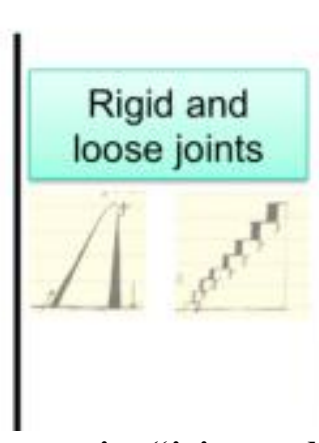

\section{K}

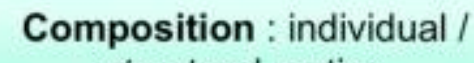
structural motive

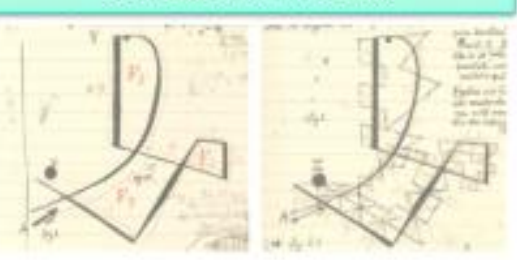

Figure 14: C-K analysis of one Klee exercise ('joints and the individual') - -initial state

\section{C}

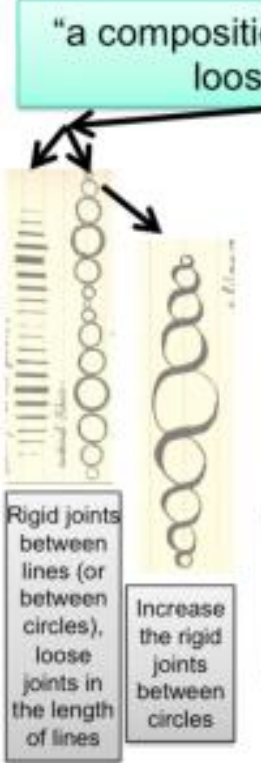

with rigid and

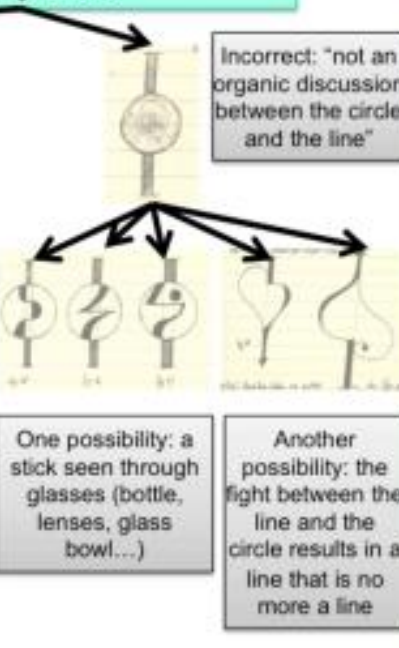

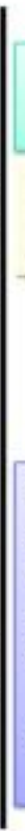

\section{K}

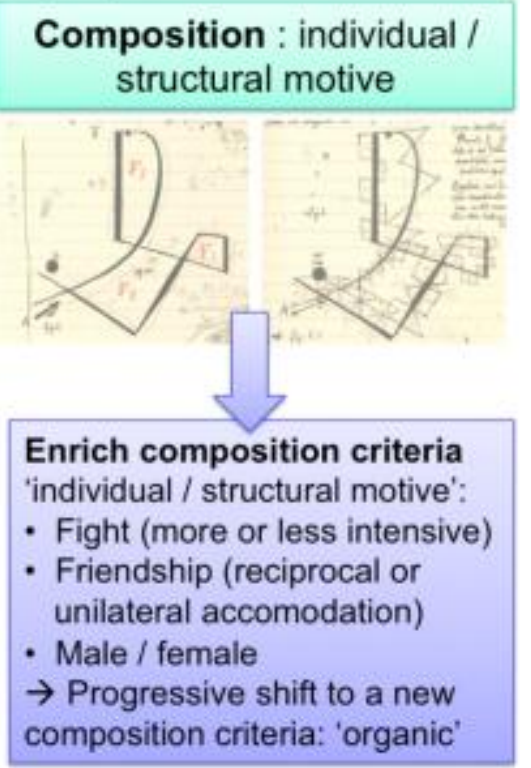

Figure 15: C-K analysis of one Klee exercise ('joints and individual') —final state (pictures from (Klee 2005)) 
For the initial state (figure 14), $\mathrm{K}$ contains the knowledge acquired during the lesson on joints and motives, while $C$ contains the brief given at the end of the lesson as homework. For the final state (figure 15), in the following course, Klee goes through the students proposals with them. His remarks are coded in C or K expansions.

This case reveals the following aspects of Klee teaching.

1- The exercise is limited to one type of composition issue (hence one dense subset) with one type of expression means (the constraints of the dense subset). Using 'joints', the artist is supposed to realize a composition via a discussion between the individual and a structural motive. Initially, the apprentice designer knows about two types of joints (rigid or loose) and about the composition of an individual based on structural motives (the previous lesson in the Klee course). The student explores how to create an 'individual' using rigid and loose joints. In his course, Klee discusses two alternatives, represented in C-space in figure 15: on the left side (in C-space, extreme far left solution), there are rigid joints between lines; on the right side (in C-space), there is an individual based on the 'discussion' between a line and a circle. The first answer ('rigid joints between lines') is said to be correct. Klee explains that there are rigid and loose joints and the articulation of rigid joints (between lines) and loose joints (in the variation of the lengths of the lines) creates an 'individual'. He proposes a variation-based on circles, where there are rigid joints between circles and loose joints in terms of the variation of circle diameters - and a variation of the variationwhere with a bolder line Klee underlines the rigid joint between the circle and the loose joint and improves the composition. Hence, even with these very limited means, it is possible to create a rigorous composition of one individual based on structural motives.

2- The exercise leads to an expansion of knowledge on expression means and composition criteria. Working on the 'incorrect answer', Klee explains that 'there is no discussion between the line and the circle; ; i.e. the play on joints does not create an individual with structural motives. Still, Klee shows that it is possible to evolve the drawing to get a correct answer. In so doing, Klee expands the expression means in that rigid and loose joints result from 'a stick seen through glasses like bottle lenses or glass bowls' or they result from the 'fight between the line and the circle', which leads to 'a line that is no more a line' and 'a circle that is no more a circle'. These 'lines', 'circles', 'stick and glasses' are new expression means for rigid and loose joints. Meanwhile, the composition criteria are enriched in that the relationship individual unity/structural motive is now 'a more or less intensive fight', or a 'friendship or reciprocal or unilateral relationship'. The individual can be a battle, or a friendship, with various criteria (e.g., intensive and reciprocal criteria). Hence, the exercise leads to the enrichment of the expression means and the composition criteria. However, this is not a form of 'densification' because the type of expression means is the same (joint) and the type of composition dimension is also the same (individual vs structural motives). Nevertheless, knowledge of these two types is denser.

3- The exercise creates a shift to another dimension in composition. The 'fight between the line and the circle' is not only a structural motive that creates an individual but also a male/female relationship that creates an 'organic discussion'. This notion of 'organic' is a new type of composition criterion in that it is not on the level of 'individual unity/structural motives' but on the level of the 'organic body/organs'. 
These three aspects are more or less present in all of Klee's exercises and contribute to the important issue of Klee's courses: teaching a design process that helps the student to be generically creative. Let's underline these three features.

1- First, Klee focuses always on the genesis of the whole, in a constantly refined partwhole relationship. Even ifeach step of teaching seems to address only one partial aspect of the final piece (e.g., perspective or balance), each of these aspects has to be consistent in itself at the level of the piece taken as a whole.In each step, Klee's teaching tends to validate a consistent part-whole relationship. Klee's lessons show that certain types of elements (e.g., lines, 'weights', rhythm, joints, and organs) are in deep correspondence with one aspect of the final piece (e.g., the perspective, balance, individual, and organism). Each lesson consists of working on the relationship between one type of language (e.g., the language of lines or, 'weight') and the aspect of the whole related to that language (e.g., the perspective or balance). This is the generalization of the exercises where Itten proposed to work on a whole montage only based on textures. Klee always teaches the whole, even if it is the whole related to its parts. In each step, Klee teaches the whole piece as expressed by one type of language (i.e., the work is seen as a perspective/lines; the work is seen as a balance/'weights'; or the work is seen as an organism/the organs and joints). One can consider this as a logic of robustness. By working in each step on the part-whole relationship, Klee ensures that each of the languages (e.g., the language of perspective or balance) expressed by specific means (e.g., lines or 'weights') is 'present' in the final piece. The languages are applicable to all known pieces and form a frame of references. Additionally, Klee ensures that the new piece that emerges can be understood in all these languages, in this frame of reference. Formally speaking, each type of language (in one step) appears as a dense subset, and this type of language (e.g., the language of perspective or balance) applies to all known pieces and each type of language corresponds to certain types of constraints (e.g., lines or weights).

2- The part-whole relationship is not a one-to-one relationship. Instead, work on the part-whole relationship expands the language of parts (involving new types of joints, line circles, and so on) and the language of the whole (involving new forms for the relationship between the individual unity and structural motives). Hence, each step of the process is also a step of creative expansion. Formally speaking, it means that Klee does not teach dense subsets as such but teaches the capacity to create dense subsets.

3- Klee proposes a logic of transitions between the process steps. Let's analyse some of these transitions. The first language is the language of lines (part) and perspective (whole). Klee suggests that these lines and perspective define horizontal and vertical and relate those to the physical notion of gravity. Having introduced that notion of gravity, lines and perspective lead to a second language, based on weights (parts) and balance (whole). In this new language, the emerging object inherits the dimensions designed with line to build perspective (i.e., hopefully original ways to treat lines and perspective) and the heritage will be expanded in the new language (where the original lines and perspective will give birth to original treatments of weights and balance). Klee then shifts from this language of weights and balance to the language of structural rhythms and the paced individual by showing that a series of weights and imbalances and balances creates forms of music. After physics and music, the third transition is based on physiology (where the rhythms and the paced individuals are animated by joints that build an organism). These transitions appear arbitrary and they are certainly. However, 
they ensure that the designer can shift from one language to the following one so that the genesis process leads to the accumulation of a growing number of languages on the object. These transitions contribute to increase the genericity of the final piece. Certainly, a master designer would not need such codified transitions and could invent his or her own. However, the designer should not neglect to invent such transitions, otherwise the genesis of his or her pieces would be limited to a (too) small number of languages, hence losing genericity. Formally speaking, this logic of transition from one language to another corresponds to a logic of countability of dense subsets. Klee teaches how to organize and walk the sequence of dense subsets.

Finally, these three features show that Klee teaches a design process where each step makes a clear contribution to the final result (feature 1), where each step can be expansive (feature 2) and the steps are linked together to form a linear evolution (feature 3). Klee teaches a process that ensures that the apprentice designer can accumulate many general languages for his or her piece, hence improving the genericity. This accumulation is based on two principles. The first is a constant concern with the 'whole', caught by dense subsets. Even if each step of the genesis addresses 'parts', each step also addresses an aspect that is valid at the level of the whole (e.g., perspective or balance). Hence, each steps leads to the 'validation' of one dimension of the 'whole' piece. The second principle is a process of accumulation that is based on neither deterministic laws nor independence principles (as in the case of systematic design) but is based on transitions between languages that keep the possibility of originality at each level (i.e., multiple paths open) and propagate the originality won at one level to the following level (i.e., there is no modularity). These transitions ensure that the genesis will accumulate as many contrasting (and still coherent) languages on the emerging piece, while keeping and increasing the generativity. This explains why this process is a generic creative design process.

Formally speaking, $\mathrm{H} 2$ and $\mathrm{H} 3$ are confirmed for Klee's teaching: generic generativity can rely on countable dense subsets.

\section{Comment on Klee's teaching: similarities and differences with engineering design approaches}

Returning to engineering design, we can only be struck by the fact that the languages of the engineering design process can precisely appear as languages of the part-whole relationship. For instance, systematic design (Pahl et al. 2007) relies on four well-identified languages: functional, conceptual, embodiment, detailed. Validating a list of requirements finally consists of checking the consistency of the emerging object on the functional dimensions. The parts are functions, while the whole is the functionality of the final object. The part-whole relationship is acceptable when the list of functions corresponds to a functional object. The same holds at the conceptual level (where the consistent combination of technical principals is supposed to address the conceptual design of the product), at the embodiment design level (where the consistent arrangement of organs is supposed to build a coherent organism) and at the detailed design level (where the fine adaptation of industrial components builds an industrially feasible product).

Still, there is one major difference between the two processes. In the logic of systematic design, designers work with a knowledge base that is structured by determinism (i.e., engineering science laws) and independences (i.e., modules). In this case, the 
interactions between the levels are simplified and purely driven by the deterministic laws (because the relationship between the languages is either a pure determinism or an independence in that either a function determines a technical principle or, by constrast, whatever the function, one technical principle can be used, namely modularity). If the knowledge base is non-deterministic and non-independent, then the transition from one language to another is no longer defined by the deterministic rules. Additionally, Klee, just like Itten, builds a knowledge base that is non-deterministic and non-independent. We find that Klee makes the same effort to always propose multiple paths (i.e., there are no deterministic rules and not one solution to an exercise given by Klee) and to always show that the attributes and the effects created at any moment in the genesis affect the rest of the design process. If there are no deterministic rules with which to structure the design process, then how is it possible to shift from one type of language to the next language, and what is the order of the process steps? The magic of Klee might lie precisely here: the invention of a logic of transitions, based on a specific language (e.g., the language of physics, music, or physiology) that might appear far from the genesis of the object but provide at least one possible order to approach many different facets of a composition.

\section{Part 5: Conclusion-discussion and further research}

We can now conclude our work and answer our research questions.

1- The courses of Itten and Klee not only aimed at teaching the past style and a new style. They also aimed at increasing students creative design capabilities and even, more precisely, at providing them techniques with which to create their own style, in the sense of being able to be generically creative. We thus confirm H1: creative design corresponds to generic generativity.

2- The analyses of the two courses identify two features critical to having a generic creative design capability.

a. A knowledge structure that is characterized by non-determinism and nonindependence. Hence, we confirm $\mathrm{H} 2$ : a splitting knowledge base is required for generic generativity.

b. A genesis process that helps to progressively 'accumulate' languages on the object in a robust way. This accumulation is based on step-by-step work on part-whole relationships and a series of transitions from one language to another one. Hence, we confirm H3: the countability of dense subsets can define a design process.

We thus confirm for Bauhaus courses the propositions that were predicted by theory. This is all the more interesting in that the propositions were not necessarily self-evident. At a time where one tends to assume that creative design is related to ideation and the birth of original ideas, design theory predicted that the knowledge structure plays an important role in generativity.

This work has an impact on several domains.

1-Regarding Bauhaus, this analysis, based on advances in design theory that today provide a unified analytical framework, helps underline that Bauhaus was neither a school 
that taught a particular style nor a school that taught design techniques but fundamentally $a$ school that taught how to systematically invent new styles.

From the perspective of style creation, we can discuss the role of technique and taste (i.e., new social trends) and their place in teaching. Surprisingly, neither Itten's nor Klee's teaching places strong emphasis on new techniques or new tastes. They more deeply focus on the reasoning logic that helps to create new style without even relying on new techniques or new 'tastes' or social trends. It was as if they were trying to teach in the 'worst case' situation. The rest of the Bauhaus program taught students how to deal with new techniques or new social trends. Based on the introductory courses, it was certainly easier to think of style creation in terms of a 'techno-push'; i.e., relying on a newly invented technique (see the work on texture, which students could freely extend to photography or today to new digital imaging) or in terms of 'market-pull' (i.e., relying on new composition dimensions as would do an artist working today on 'sustainability' or 'transparency').

More generally, this work provides a deeper understanding of the relationship between art and technique in design. The use of 'texture' or more generally 'expression means' is just a technique. However, they are not necessarily splitting or non-splitting. The art of designers is not limited to making use of a technique to design an object. More generally, design consists of mobilizing a technique to build a knowledge base that is splitting or not.

2-This work provides results for engineering design. The comparison helps show that systematic design is precisely characterized by knowledge structures that prevent the splitting condition and that are characterized by independence (modularity) and determinism (engineering science). This clarifies one critical aspect of systematic design, namely avoiding 'going out of the box'; i.e., avoiding generic generativity. Modular and deterministic generativity might be encouraged, as long as they create a knowledge base that remains non-splitting.

From this perspective, we can wonder whether compatibility with the splitting condition could characterize professions. We should insist here that the logic of designing with (respectively without) the splitting condition is not intrinsically the logic of engineering design (respectively industrial design). Engineering design can also be driven by a logic of innovative design. Several works have long underlined a logic of breakthrough and unknown exploration in engineering design (Kroll 2013 ; Kroll, Le Masson et Weil 2014 ; Shai et al. 2013 ; Taura et Nagai 2012). This is deeply coherent with the results of this paper: in innovative design, engineers reverse the logic, they use engineering science and engineering techniques to build a knowledge base that follows the splitting condition (see in particular the analysis of breakthrough projects in military weapons published by (Lenfle, Le Masson et Weil 2014, 2015)).

Conversely, generic generativity might not necessarily be the logic of industrial design. In some cases, industrial design might favour the elaboration of knowledge bases that are nonsplitting. An interesting illustration of this situation is the very early integration of 'industrial designers' in industrial processes by Wedgewood, the famous earthenware inventor, in the late $18^{\text {th }}$ century (Forty 1986), where designers were actually in charge of inventing the forms of plates that would support several, varied ornaments. Today the talent of designers might precisely be to create knowledge bases that are locally splitting and non-splitting.

3-This work contributes to the debate on the relationship between engineering design and industrial design and their respective roles in the design processes. It underlines that the critical activity is not only the creation of a new artefact but it is also the moment where designers 'prepare' their knowledge base, to 'split' it (or to 'unsplit' it). Both actions (splitting 
and unsplitting) are important. It might be that industrial design could help engineers split their knowledge base, if necessary, to open paths to innovative design. Conversely, engineers might help industrial designers to 'unsplit' their knowledge base to facilitate rulebased design (see, (Brun, Le Masson et Weil 2015)).

4-Finally, this work contributes to design theory. We began the paper with a condition on generativity. This appears as a 'negative' result of the theory, whereas we tend to think that the only limit to generativity is fixation and imagination capacity, design theory predicts that there is also a condition on the structure of knowledge used in the design process - the knowledge base has to meet the splitting condition. The work on Bauhaus leads to the positive interpretation of this condition in that it shows that teachers in the field of design are actually able to help students build a knowledge base that meets the splitting condition. Teaching design (for generic generativity) finally consists of enabling the splitting condition. Hence, our study on Bauhaus teaching also raises a question on design education: does design education today (be it engineering design education or industrial design education) teach 'splitting knowledge' or, even more, does it provide students the capacity to themselves acquire and create new knowledge to meet the splitting condition?

\section{References}

Bach Cv (1896) Die Maschinen-Elemente, ihre Berechnung und Konstruktion : Mit Rücksicht auf die neueren Versuche 5. vermehrte Auflage edn. Verlag der J. G. Cotta'schen Buchhandlung, Stuttgart

Bach Cv (1924) Die Maschinen-Elemente, ihre Berechnung und Konstruktion : Mit Rücks. aufd. neueren Versuche 12. verm. Aufl. edn. Kröner, Leipzig

Bense M (1956) Aesthetica II. Agis, Baden-Baden

Betts P (1998) Science, semiotics and society: The Ulm Hochschule für Gestaltung in Retrospect. Design Issues 14 (2):67.

Blossfeldt K, Nierendorf K (1928) Urformen der Kunst: photographische Pflanzenbilder. Verlag Ernst Wasmuth, A.G., Berlin

Boden MA (1999) Computer Models of Creativity. In: Sternberg RJ (ed) Handbook of creativity. Cambridge University Press, Cambridge, pp 351-372

Braha D, Reich Y (2003) Topologial structures for modelling engineering design processes. Research in Engineering Design 14 (4):185-199.

Brun J, Le Masson P, Weil B (2015) Analyzing the generative effects of sketches with design theory: sketching to foster knowledge reordering. In: International Conference on Engineering Design, Milan, 2015. p Reviewers'favorite award ICED'15

Campbell J (1978) The German Werkbund. The Politics of Reform in the Applied Arts. Princeton University Press, Princeton, NJ

Chow TY (2009) A beginner's guide fo Forcing. In: Chow TY, Isaksen DC (eds) Communicating Mathematics - A conference in honor of Joseph A. Gallian's 65th Birthday, vol 479. Amercian Mathematical Society, Providence, Rhode Island, pp 25-40

Cohen P (1966) Set Theory and the Continuum Hypothesis. Addison-Wesley,

Cohen P (2002) The discovery of Forcing. Rocky Mountain Journal of Mathematics 32 (4):1071-1100. 
Dehornoy P (2010) Théorie axiomatique des ensembles. In: Encyclopeadia Universalis. Paris, p 20

Dickman B (2013) Mathematical Creativity, Cohen Forcing, and Evolving Systems: Elements for a Case Study on Paul Cohen. Journal of Mathematics Education at Teachers College 4 (2):50-59.

Dorst K, Vermaas PE (2005) John Gero's Function-Behaviour-Structure model of designing: a critical analysis. Research in Engineering Design 16 (1-2):17-26.

Dow AW (1920) Composition: A Series of Exercises in Art Structure for the Use of Students and Teachers. DOubleday, Page \& Company, Garden City, NY

Droste M (2002) Bauhaus 1919-1933. Taschen, Köln

Engler F, Lichtenstein C (1990) Streamlined, A Metaphor for Progress, The Esthetics of Minimized Drag. Lars Müller Publishers, Baden, Suisse

Findeneisen F (1950) Neuzeitliche Maschinenelemente. Schweizer Druck- und Verlaghaus AG, Zürich

Forty A (1986) Objects of desire. 2ème édition, première édition en 1986 edn. Thames \& Hudson, London

Friedewald B (2011) Paul Klee, Life and Work. Prestel, Munich

Froissart-Pezone R (2004) L'Ecole à la recherche d'une identité entre art et industrie (1877-1914). In: Raynaud P (ed) Histoire de l'Ecole nationale supérieure des arts décoratfs 1ère partie (1766-1941). Edition spéciale du Journal de l'Ensad, Paris, pp 108-147

Gardner H (1936) Art Through the Ages - An Introduction to its History and Significance. Second Edition edn. Harcourt, Brace and Company, New York

Gropius W (1923) The Theory and Organization of the Bauhaus.

Gropius W (1925) Neue Bauhauswerkstätten.

Guilford JP (1950) Creativity. American Psychologist 3:444-454.

Hadamard J (1945) The psychology of invention in the mathematical field. Princeton University Press, New York

Hatchuel A, Le Masson P, Reich Y, Weil B (2011) A systematic approach of design theories using generativeness and robustness. In: International Conference on Engineering Design, ICED'11, Copenhagen, Technical University of Denmark, 2011. $\mathrm{p} 12$

Hatchuel A, Weil B (2009) C-K design theory: an advanced formulation. Research in Engineering Design 19 (4):181-192.

Hatchuel A, Weil B, Le Masson P (2013) Towards an ontology of design: lessons from C-K Design theory and Forcing. Research in Engineering Design 24 (2):147-163.

Heymann M (2005) "Kunst" und Wissenchsaft in der Technik des 20. Jahrhunderts. Zur Geschichte der Konstruktionswissenschaft. Chronos Verlag, Zürich

Hubka V, Eder WE (1988) Theory of technical systems. A total Concept Theory for Engineering Design. Springer,

Itten J (1961) The art of color. John Wiley \& Sons, Inc., New York, NY

Itten J (1975) Design and Form, the Basic Course at the Bauhaus and Later. Revised edition (first edition 1963) edn. John Wiley and Sons, Inc., London

Jaffee B (2005) Before the New Bauhaus: From Industrial Drawing to Art and Design Education in Chicago. Design Issues 21 (1):41-62.

Jansson DG, Smith SM (1991) Design Fixation. Design Studies 12 (1):3-11.

Jech T (2002) Set Theory. Springer Monographs in Mathematics, 3rd millenium edition, revised and expanded edn. Springer, Berlin

Kanamori A (2008) Cohen and Set Theory. Bulletin of Symbolic Logic 14 (03):351-378. 
Kandinsky W (1975) Cours du Bauhaus (1929). Traduit de l'allemand d'après des notes manuscrites par Suzanne et Jean Leppien edn. Denoël, Paris

Keane W (2003) Semiotics and the social analysis of material things. Language and Communication 23:409-425.

Kesselring F (1942) Die "starke" Konstruktion, Gedanken zu einer Gestaltungslehre. Zeitschrift des Vereines deutscher Ingenieure 86 (21/22 30. Mai 1942 und 49/50 12. Dez. 1942):pp. 321-330 und 749-752.

Klee P (1922) Beiträge zur bildnerischen Formlehre ('contribution to a pictorial theory of form', part of Klee 1921-2 lectures at the Bauhaus). Weimar

Klee P (1966) On modern Art. Faber and Faber Limited, London

Klee P (2005) Cours du Bauhaus, Weimar 1921-1922. Contributions à la théorie de la forme picturale. Hazan, Paris

König W (1999) Künstler und Strichezieher. Konstruktions- und Technikkulturen im deutschen, britischen, amerikanischen und französischen Maschinenbau zwischen 1850 und 1930, vol 1287. Suhrkamp Taschenbuch Wissenschaft. Suhrkamp Verlag, Frankfurt am Main

Krippendorff K (1989) On the Essential Contexts of Artifacts or on the Proposition That "Design Is Making Sense (Of Things)". Design Issues 5 (2):9-39.

Kroll E (2013) Design theory and conceptual design: contrasting functional decomposition and morphology with parameter analysis. Research in Engineering Design 24 (2):165-183.

Kroll E, Le Masson P, Weil B (2014) Steepest-first exploration with learning-based path evaluation: uncovering the design strategy of parameter analysis with $\mathrm{C}-\mathrm{K}$ theory. Research in Engineering Design 25:351-373.

Laudien K (1931) Maschinenelemente. Dr. Max Junecke Verlagsbuchhandlung, Leipzig

Le Masson P, Dorst K, Subrahmanian E (2013) Design Theory: history, state of the arts and advancements. Research in Engineering Design 24 (2):97-103.

Le Masson P, Hatchuel A, Weil B (2011) The Interplay Between Creativity issues and Design Theories: a new perspective for Design Management Studies? Creativity and Innovation Management 20 (4):217-237.

Le Masson P, Weil B (2013) Design theories as languages for the unknown: insights from the German roots of systematic design (1840-1960). Research in Engineering Design 24 (2):105-126.

Lenfle S, Le Masson P, Weil B (2014) Using design theory to characterize various forms of breakthrough R\&D projects and their management: revisting manhattan and polaris. Paper presented at the European Academy of Management, Valencia, Spain,

Lenfle S, Le Masson P, Weil B (2015) When project management meets design theory: revisiting the Manhattan and Polaris projects to characterize "radical innovation" and its managerial implications. Creativity and Innovation Management ((accepted)).

Leniaud J-M (1994) Viollet-le-Duc ou les délires du système. Menges, Paris

Lindemann U (2010) Systematic Procedures Supporting Creativity - A Contradiction? . In: Taura T, Nagai Y (eds) Design creativity. Springer, London, pp 23-28

Maldonado T (1960) New developments in Industry and the Training of Designers. Architects' yearbook 9:174-180.

Meurer M (1896) Die Ursprungsformen des griechischen Akanthusornamentes und ihre natürlichen Vorbilder. G. Reimer, Berlin 
Moholy-Nagy (1938) The New Vision: Fundamentals of Bauhaus Design, Painting, Sculpture, and Architecture. Norton, New-York

Moore GH (1988) The origins of forcing (Logic colloquium '86). In: Drake FR, Truss JK (eds) Studies in logic and the foundations of mathematics. North-Holland, Amsterdam, pp 143-173

Pahl G, Beitz W, Feldhusen J, Grote K-H (2007) Engineering design, a systematic approach (trans: Wallace K, Blessing L, Bauert F). Third English edition edn. Springer, London

Poincaré H (1908) La création mathématique. Bulletin de l'Institut Général de Psychologie 8 (3).

Raynaud P (ed) (2004) Histoire de l'Ecole nationale supérieure des arts décoratfs 1ère partie (1766-1941). Edition spéciale du Journal de l'Ensad,

Read H (1959) A concise history of modern painting. Praeger, London

Redtenbacher F (1852) Prinzipien der Mechanik und des Maschinenbaus. Bassermann, Mannheim

Reich Y (1995) A Critical Review of General Design Theory. Research in Engineering Design 7:1-18.

Reuleaux F (1877) Briefe aus Philadelphia. Druck und Verlag von Friedrich Vieweg und Sohn, Braunschweig

Reuleaux F, Moll CL (1862) Constructionslehre für den Maschinenbau, erster Band : die Construction der Maschinentheile. Fridriech Vieweh und Sohn, Braunschweig

Rhodes M (1961) An Analysis of Creativity. The Phi Delta Kappan 42 (7):305-310.

Riccini R (1998) History from things: Notes on the history of industrial design. Design Issues 14 (3):43.

Rice P (1994) An engineer imagines. Artemis,

Rodenacker WG (1970) Methodisches Konstruieren. Konstruktionsbücher. Springer Verlag, Berlin

Ross DW (1907) A Theory of Pure Design: Harmony, Balance, Rhythm. Houghton, Mifflin and Company, Boston and New York

Rötscher F (1927) Die Maschinenelemente. Verlag von Julius Springer, Berlin

Schwartz FJ (1996) The Werkbund, Design Theory and Mass Culture Before the First World War. Yale University Press, New Haven and London

Shai 0, Reich Y (2004a) Infused Design: I Theory. Research in Engineering Design 15 (2):93-107.

Shai 0, Reich Y (2004b) Infused Design: II Practice. Research in Engineering Design 15 (2):108-121.

Shai O, Reich Y, Hatchuel A, Subrahmanian E (2013) Creativity and scientific discovery with infused design and its analysis with $\mathrm{C}-\mathrm{K}$ theory. Research in Engineering Design 24 (2):201-214.

Stoots J (2011) Karl Blossfeldt, Indisputably Modern. In: Rooco V (ed) European Photo Avant-garde, 1920s-1930s.

Taura T, Nagai Y (2012) Concept Generation for Design Creativity: A Systematized Theory and Methodology. Springer,

Taura T, Nagai Y (2013) A Systematized Theory of Creative Concept Generation in Design: First-order and high-order concept generation. Research in Engineering Design 24 (2):185-199.

Tomiyama T, Yoshikawa H (1986) Extended general design theory. vol CS-R8604. Centre for mathematics and Computer Science, Amsterdam, the Netherlands

Vitruvius (1999) Ten Books on Architecture. Cambridge University Press, Cambridge, UK 
Wallas G (1926) The Art of Thought. Harcourt Brace, New York

Weisberg RW (1992) Creativity Beyond The Myth of Genius. W. H. Freeman Company, New York

Whitford F (1984) Bauhaus. world of art. Thames \& Hudson, London

Wick RK (2000) Teaching at the BAuhaus. Hatje Cantz,

Yoshikawa H (1981) General Design Theory and a CAD System. In: Sata T, Warman E (eds) Man-Machine Communication in CAD/CAM, proceedings of the IFIP WG5.25.3 Working Conference 1980 (Tokyo). Amsterdam, North-Holland, pp 35-57 